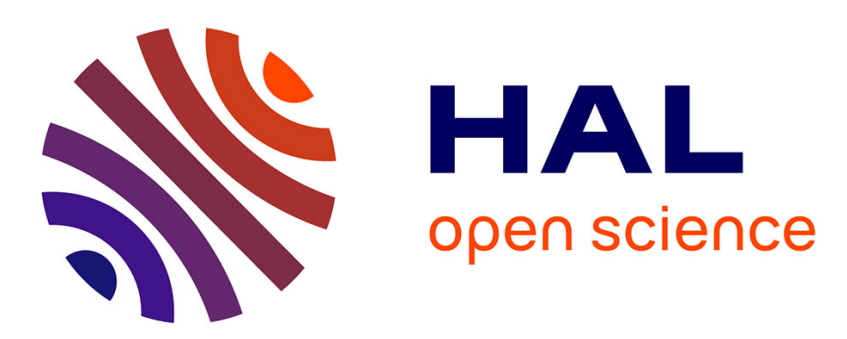

\title{
Effect of an Accessibility Measure in a Model for Choice of Residential Location, Workplace, and Type of Employment
}

Ignacio Inoa, Nathalie Picard, André de Palma

\section{To cite this version:}

Ignacio Inoa, Nathalie Picard, André de Palma. Effect of an Accessibility Measure in a Model for Choice of Residential Location, Workplace, and Type of Employment. 2014. hal-00964212

\author{
HAL Id: hal-00964212 \\ https://hal.science/hal-00964212 \\ Preprint submitted on 24 Mar 2014
}

HAL is a multi-disciplinary open access archive for the deposit and dissemination of scientific research documents, whether they are published or not. The documents may come from teaching and research institutions in France or abroad, or from public or private research centers.
L'archive ouverte pluridisciplinaire HAL, est destinée au dépôt et à la diffusion de documents scientifiques de niveau recherche, publiés ou non, émanant des établissements d'enseignement et de recherche français ou étrangers, des laboratoires publics ou privés. 
EFFECT OF AN ACCESSIBILITY MEASURE IN A MODEL FOR CHOICE OF RESIDENTIAL LOCATION, WORKPLACE, AND TYPE OF EMPLOYMENT

Ignacio A. INOA

Nathalie PICARD

André de PALMA

Cahier $n^{\circ}$ 2014-07

\section{DEPARTEMENT D'ECONOMIE}

Route de Saclay

91128 PALAISEAU CEDEX

(33) 169333033

http://www.economie.polytechnique.edu/

mailto:chantal.poujouly@polytechnique.edu 


\title{
Effect of an Accessibility Measure in a Model for Choice of Residential Location, Workplace, and Type of Employment*
}

\author{
Ignacio A. Inoa ${ }^{1}$, Nathalie Picard ${ }^{1,3}$, and André de Palma $a^{2,3}$ \\ ${ }^{1}$ Université de Cergy-Pontoise, Thema ${ }^{\dagger}$ \\ ${ }^{2}$ École Normale Supérieure de Cachan, CES $\ddagger$ \\ ${ }^{3}$ École Polytechnique, Département d'Economie ${ }^{\S}$
}

September 2013

\begin{abstract}
A three-level nested logit model for the choice of residential location, workplace, and type of employment is used to assess the effect of an individual-specific measure of accessibility to employments that takes into account the attractiveness of different occupations when the choice of workplace is anticipated in the decision of residential location. The model allows for variation in the preferences for types of employment across individuals and accounts for individual heterogeneity of preferences at each choice level in education, age, gender, and children. Using data from the Île-de-France region, it shows that the individualspecific accessibility measure is an important determinant of the choice of residential location and its effect differs along the life cycle. The attractiveness of the types of employment is a better predictor of the workplace location than the usual total number of employments.
\end{abstract}

Keywords: residential location, employment location, accessibility, nested logit, Île-de-France.

JEL Codes: R21, C35, C51.

*The authors thank Kiarash Motamedi and Mohammad Saifuzzaman for their help in computing travel time, Ismir Mulalik, Robert Pollak, and participants at the 2012 Bari XIV SIET conference, the 2012 Lausanne SustainCity consortium meeting and the THEMA seminar for useful discussion. The research was funded by Ademe and DRI (Direction de la recherche et de l'innovation du ministère chargé du développement durable) as part of the French national research programme in land transportation PREDIT. The authors thank the anonymous referees. All remaining errors and deficiencies are the responsibility of the authors.

†133, boulevard du Port, 95011 Cergy-Pontoise Cedex, France, ignacio.inoa@u-cergy.fr, nathalie.picard@u-cergy.fr

$\ddagger 61$, avenue du président Wilson, 94230 Cachan Cedex, France, andre.depalma@ens_cachan.fr

${ }^{\S}$ Route de Saclay, 91128 Palaiseau, France. 


\section{Introduction}

Choice models of location have been estimated conditional either on workplace or on residential location. The first discrete choice models applied to residential location (Lerman, 1976; McFadden, 1978; Anas, 1981) borrowed the assumption of the exogenous determination of workplace location from the monocentric models (Alonso, 1964; Muth, 1969; Mills, 1972). Siegel (1975) and Simpson (1980) extended the monocentric model allowing a simultaneous choice of workplace and residential location and Linneman et al. (1983) used the joint multinomial logit model for residential migration and job search.

The assumption of exogenous workplace in choice models of residential location has been questioned since the empirical results of Waddell (1993), who showed that a joint logit model of workplace, tenure, and residential location outperform a nested logit model for the choice of tenure and residential location, conditional on workplace.

On the one hand, residential location choice models have been studied in connection with mobility or relocation (Clark et al., 1999; Lee et al., 2010), mode choice (Eliasson et al., 2000), and accessibility (Ben-Akiva et al., 1998). On the other hand, choice models of workplace location have been mostly developed in the framework of aggregated travel models.

Discrete choice models of both residential location and workplace have also been addressed from the point of view of the multi-worker household. Freedman et al. (1997) and Abraham et al. (1997) studied the influence of spouses' earnings and commuting time on the choice of the household residential location and the spouses' workplaces to study how the employment opportunities for the wife influence the choice of workplace of both spouses and the household residential location. Waddell et al. (2007) adapted methods of market segmentation in a discrete choice model of joint residential location and workplace for single-worker households to model the probability of choosing residential location or workplace first. Doing so, no a priori assumption 
is necessary on the exogenous choice (workplace and residential location can be chosen in any order) and the probability of making one choice before the other depends on household characteristics.

Crane (1996) and Kan (1999; 2002) deal with the effect of changes in the type of employment on residential mobility, mobility expectation, and commuting behavior. Palma et al. (2008) review the implications of risk and uncertainty in the framework of discrete choice models in residential location and transportation. Cohen (2013) provides in this issue an introduction to decision-making under risk and uncertainty in the (non-)expected utility framework. Ben-Akiva et al. (2012) review processes and contexts in discrete choice models.

Commuting time is one of the main determinants of residential location. It depends on both household location and workplace, which themselves result from a two-stage decision process. The second-stage decision is conditioned on the first stage, and the second stage is anticipated in the first stage. Workers choose a workplace conditional on their actual residential location (second stage), and anticipate their potential workplaces (employment opportunities), when choosing their residential location (first stage). Actual commuting time explains the choice of workplace location (Abraham et al., 1997; Levine, 1998), while accessibility to employments explains the choice of residential location (Anas, 1981; Ben-Akiva et al., 1998; Levinson, 1998).

Which decision, workplace or residential location, is made first is an open question. Does workplace influence residential location or conversely? This dependency is affected by the the household's life cycle, by the rigidities in the real estate and labor markets, by the availability of employments, and by the demographic and socioeconomic characteristics of households (Waddell, 1993; Waddell et al., 2007). Discrete choice models (Ben-Akiva et al., 1985; Anderson et al., 1992) allow us to study the interdependency in the choices of location (nested models). They let the choice of residence (and of workplace) appear 
as a trade-off between local characteristics varying across socio-demographic segments (Sermons et al., 2001; Bhat et al., 2004).

We develop a three-level nested logit model of the interdependency of residential location and workplace, accounting for the variation across individuals in the preferences for types of employment. Residential location is the highest level choice; workplace location is the intermediate level choice; and the type of employment is the lowest level. This nested structure allows us to build an individual-specific accessibility measure, which corresponds to the expected maximum utility across all potential workplace locations. When considering accessibility to employments, the choice of a particular workplace is influenced by the distribution of employments of the same type of the worker. This threelevel nested logit configuration also allows us to build an individual-specific measure of attractiveness to types of employment.

\section{Risk and information in discrete choice models}

Each household chooses a single alternative from the choice set $\mathcal{L}$, with $|\mathcal{L}|=L$. The set $\mathcal{L}_{0}$ of possible alternatives is partitioned into $I$ choice sets $\mathcal{L}_{i}, i=$ $1, \ldots, I$, also called nests. $\mathcal{L}_{i}$ represents the nest containing a given alternative $i, i \in \mathcal{L}_{0}$. The list of nests is assumed to be exogenous and identical for all decision makers. The utility of individual $n$ choosing alternative $i$ is a random variable given by $U_{n}(i)=V_{n}(i)+\varepsilon_{n}(i)$, where $V_{n}(i)$ is the deterministic utility, and where $\varepsilon_{n}(i)$ is an absolutely continuous random variable. The random term $\varepsilon_{n}(i)$ is an error term unknown to the modeler, covering the unobservable individual or unknown characteristics (Manski et al., 1977). Such models are also referred to as additive random utility models (McFadden, 1978; Anderson et al., 1992). Alternatively, the error term $\varepsilon_{n}(i)$ can be interpreted as a match value between the individual $n$ and the alternative $i$. The modeler is assumed to know the distribution of the error terms, but not their specific values. In the cases analyzed below, we make different assumptions about the level 
of information available to the decision maker at the different stages of the decision process (before or after the individual chooses a set of alternatives).

The expected value of $\varepsilon_{n}(i)$ is set to zero without loss of generality, and its standard deviation is assumed to be the same across alternatives and denoted by $\mu$. According to the law of comparative judgments (Thurstone, 1927), the decision maker knowing the realization of $\varepsilon_{n}(i), i \in \mathcal{L}$, selects the alternative with the highest utility. Formally, the probability that the individual $n$ selects the alternative $i$ in the choice set $\mathcal{L}$ is:

$$
\mathbb{P}_{n}(i \mid \mathcal{L})=\operatorname{Pr}\left(U_{n}(i) \geqslant U_{n}\left(i^{\prime}\right), \forall i^{\prime} \in \mathcal{L}\right)
$$

We shall extend this formula to the case where the decision maker ignores the realization of $\varepsilon_{n}(i)$. In the MNL model, the error terms are assumed to be independent and identically distributed (i.i.d.). Their common law is Gumbel or double exponential distributed, with:

$$
\mathbb{P}(\varepsilon \leq x)=\exp \left(-\exp \left(\frac{-(x+\gamma)}{\mu}\right)\right)
$$

where the shift parameter $\gamma \simeq 0.5772$ is the Euler constant. It guarantees that $\mathbb{E}(\varepsilon)=0$. The standard deviation of $\varepsilon$ is proportional to the scale parameter $\mu$. The CDF of a standard Gumbel distribution is $\mathbb{P}(\varepsilon \leq x)=\exp (-\exp (-x))$; its expectation is $\gamma$ and its standard deviation is $\frac{\pi}{\sqrt{6}}$ (this corresponds to $\mu=1$ ). The PDF of this standard random variable is denoted by $f$ and given by $f(x)=\exp (-x) \exp (-\exp (-x))$.

When the error terms are i.i.d. Gumbel with scale parameter $\mu$, the choice probabilities have the closed form (McFadden, 1978):

$$
\mathbb{P}_{n}(i \mid \mathcal{L})=\frac{\exp \left(\frac{V_{n}(i)}{\mu}\right)}{\sum_{i^{\prime} \in \mathcal{L}} \exp \left(\frac{V_{n}\left(i^{\prime}\right)}{\mu}\right)}, i \in \mathcal{L} .
$$

The same expression holds for any shift parameter other than $\gamma$ or 0 . 
Consider two alternatives $i_{1}$ and $i_{2}$ included in two choice sets $\mathcal{L}_{1}$ and $\mathcal{L}_{2}$. The property

$$
\begin{aligned}
& \frac{\mathbb{P}_{n}\left(i_{1} \mid \mathcal{L}_{1}\right)}{\mathbb{P}_{n}\left(i_{2} \mid \mathcal{L}_{1}\right)}= \frac{\frac{\exp \left(\frac{V_{n}\left(i_{1}\right)}{\mu}\right)}{\sum_{i^{\prime} \in \mathcal{L}} \exp \left(\frac{V_{n}\left(i^{\prime}\right)}{\mu}\right)}}{\frac{\exp \left(\frac{V_{n}\left(i_{2}\right)}{\mu}\right)}{\sum_{i^{\prime} \in \mathcal{L}} \exp \left(\frac{V_{n}\left(i^{\prime}\right)}{\mu}\right)}}=\frac{\exp \left(\frac{V_{n}\left(i_{1}\right)}{\mu}\right)}{\exp \left(\frac{V_{n}\left(i_{2}\right)}{\mu}\right)} \\
&= \frac{\frac{\exp \left(\frac{V_{n}\left(i_{1}\right)}{\mu}\right)}{\sum_{i^{\prime \prime} \in \mathcal{L}^{\prime}} \exp \left(\frac{V_{n}\left(i^{\prime \prime}\right)}{\mu}\right)}}{\exp \left(\frac{V_{n}\left(i_{2}\right)}{\mu}\right)} \\
&= \frac{\sum_{i^{\prime \prime} \in \mathcal{L}^{\prime}} \exp \left(\frac{V_{n}\left(i^{\prime \prime}\right)}{\mu}\right)}{\mathbb{P}_{n}\left(i_{1} \mid \mathcal{L}_{2}\right)} \\
& \mathbb{P}_{n}\left(i_{2} \mid \mathcal{L}_{2}\right)
\end{aligned}
$$

corresponds to the independence of irrelevant alternatives (IIA), which characterizes the multinomial logit model. The relative probability that the individual $n$ selects the alternative $i_{1}$ rather than the alternative $i_{2}$ is the same in all the choice sets containing both $i_{1}$ and $i_{2}$.

An individual who chooses between different choice sets needs to evaluate the benefit (or surplus) of the different choice sets beforehand, before the choice is made based on the information available at that stage.

The terminology ex-ante and ex-post characterizes the level of information available to the decision maker. The ex-ante utility of the choice set $\mathcal{L}$ corresponds to the value associated to $\mathcal{L}$ before selection. The ex-post utility of the choice set $\mathcal{L}$ corresponds to the value associated to $\mathcal{L}$ after selection, based on the information available at that stage. We present the different cases. 


\subsection{Information revealed ex-post}

This case is the learning case. The individual has no information ex-ante about the exact value of the individual terms, but acquires such information after selecting the choice set.

After selecting the choice set, the individual becomes acquainted with the individual terms and observes the realizations $e_{n} \equiv\left(e_{1}, \ldots, e_{L}\right)$ of the random terms $\varepsilon_{n}(1), . ., \varepsilon_{n}(L)$. Once the choice set $\mathcal{L}$ is selected, the utility of alternative $i$ is a number denoted by $\tilde{U}_{n}(i)=V_{n}(i)+e_{i}, i=1, \ldots, L$. The ex-post value of the utility of the choice set $\mathcal{L}$ is a number equal to:

$$
\tilde{U}_{n}\left(\mathcal{L} ; e_{n}\right)=\max _{i \in \mathcal{L}} \tilde{U}_{n}(i)
$$

Ex-ante, the values of the error terms are unknown, but the probability distribution of $\varepsilon_{n}(1), \ldots, \varepsilon_{n}(L)$, evaluated at any point $\mathbf{e}_{n}$, is known and given by $f\left(e_{1}\right), f\left(e_{2}\right), \ldots f\left(e_{L}\right)$. The surplus of the choice set $\mathcal{L}$ corresponds to its expected utility, computed ex-ante:

$$
\mathbb{E} U_{n}(\mathcal{L}) \equiv \int_{\mathbb{R}^{L}} \tilde{U}_{n}\left(\mathcal{L} ; \mathbf{e}_{n}\right) f\left(e_{1}\right) f\left(e_{2}\right) \ldots f\left(e_{L}\right) d e_{1} d e_{2} \ldots d e_{L}
$$

Eq. (6) is in the vein of the von Neumann-Morgenstern expected utility function, involving the computation of $L$ integrals.

With the Gumbel specification, the ex-ante utility of the choice set $\mathcal{L}$ is a surplus corresponding to the expected utility of the choice set $\mathcal{L}$ (Ben-Akiva et al., 1985):

$$
S_{n}(\mathcal{L}) \equiv \mathbb{E} U_{n}(\mathcal{L})=\mu \ln \left(\sum_{i \in \mathcal{L}} \exp \left(\frac{V_{n}(i)}{\mu}\right)\right) .
$$

If, without loss of generality, $V_{n}(1)<\ldots<V_{n}(i)<\ldots V_{n}(L)$, then,

$$
\lim _{\mu \rightarrow 0} \mathbb{E} U_{n}(\mathcal{L})=V_{n}(L)
$$

When the individual terms vanish, the model becomes deterministic. In this 
case, the individual $n$ selects the best alternative $L$ with probability 1 and obtains the utility $V_{n}(L)$.

Moreover, as the variance of the individual terms is very large, each MNL choice probability tends to $1 / L$ and the expected utility of the chosen alternative tends to infinity:

$$
\lim _{\mu \rightarrow \infty} \mathbb{E} U_{n}(\mathcal{L})=\infty
$$

This is because the maximum of i.i.d. Gumbels has a Gumbel distribution with the same variance (here $\mu$ which tends to infinity) and with the same expected value (here tending to infinity).

As expected, the attractiveness of a choice set increases with additional alternatives.

$$
\text { If } \begin{aligned}
V_{n}(1)=\ldots .=V_{n}(i)= & \ldots=V_{n}(L) \equiv V_{n}, \\
& \mathbb{E} U_{n}(\mathcal{L})=V_{n}+\mu \ln (L),
\end{aligned}
$$

so that the marginal contribution of an extra alternative decreases when the total number of alternatives increases. The expected utility is an increasing and concave function of the total number of alternatives $L$.

\subsection{Information available ex-ante}

This is the full-information case. The decision maker knows the value of the individual terms beforehand. Therefore the ex-ante value of the utility of the choice set is the same as its ex-post value. This common value is equal to:

$$
\tilde{U}_{n}\left(\mathcal{L} ; e_{n}\right)=\max _{i \in \mathcal{L}} \tilde{U}_{n}(i)
$$

This common value is also equal to the ex-post value of the choice set in Eq. (11), when information is revealed only ex-post. By contrast, the ex-ante value of the choice set depends on whether the decision maker has the piece of information ex-ante. Ex-ante information has a strictly positive value because 
it helps the decision maker to select the choice set, a fact presented in Table 1 .

\section{[Insert Table 1}

Consider two choice sets containing two alternatives each. The expected utility $V_{i}, i=1, \ldots, 4$ is equal to 0 for the two alternatives of the first choice set, and is equal to 1 for the two alternatives of the second choice set. The realizations $e_{i}, i=1, \ldots, 4$ of the random terms are $(2,1)$ for the first choice set and $(0,-1)$ for the second one. The utilities $U_{i}, i=1, \ldots, 4$ are then $(2,1)$ in the first choice set and $(1,0)$ in the second choice set. In the absence of information ex-ante, the decision maker ignores the realizations $e_{i}$ of the random variables. Therefore, these realizations are i.i.d. across alternatives, the decision maker selects the second choice set (with the highest expected utility $V_{i}$ ) at the first stage of the choice process. Once this choice set is selected, the decision maker observes the realizations in this choice set, and selects the third alternative (because it has the highest utility $U_{i}$ in the chosen choice set).

By contrast, with information obtained ex-ante, the decision maker selects the first choice set and the first alternative. The decision maker acts as in a one-step choice process, as in a selection among the full set of alternatives (alternative 1).

In the learning case, the choice set selected ex-ante often differs (as in the example above) from the choice set, which is the best ex-post in the second step. The decision maker selects the alternative that is the best ex-post in the small choice set selected in the first step, but the alternative finally selected is usually not optimal ex-post in the full choice set. This implies that, in the learning case, a suboptimal alternative is selected when the alternative, which is optimal ex-post, is not included in the choice subset that is optimal ex-ante.

The individual-specific value of the choice set in the full information case holds for the decision maker $n$, characterized by the realization $e_{n} \equiv\left(e_{1}, \ldots, e_{L}\right)$. The decision maker knows this value ex-ante, but the modeler knows it neither 
ex-ante nor ex-post. The modeler ignores the realizations of individual error terms for a given individual, but knows the probability $f\left(e_{1}\right) f\left(e_{2}\right) \ldots f\left(e_{L}\right)$ $d e_{1} d e_{2} \ldots d e_{L}$ with which the individual terms lie in the infinitesimal hypercube $d\left(e_{n}\right) \equiv d e_{1} d e_{2} \ldots d e_{L}$. The expected utility of the choice set $\mathcal{L}$ for the individual $n$, computed by the modeler who ignores the value of the individual taste, is:

$$
\int_{\mathbb{R}^{L}} \tilde{U}_{n}\left(\mathcal{L} ; e_{n}\right) f\left(e_{1}\right) f\left(e_{2}\right) \ldots . f\left(e_{L}\right) d e_{1} d e_{2} \ldots d e_{L} .
$$

The probability, computed by the modeler, that the individual $n$ chooses the alternative $i$ in the choice set $\mathcal{L}$ corresponds to the probability that the vector $e_{n}$ lies in the region $\left\{V_{n}(i)+e_{n}(i)>V_{n}\left(i^{\prime}\right)+e_{n}\left(i^{\prime}\right) ; \forall i^{\prime} \in \mathcal{L}\right\}$. It is given by the MNL formula in Eq. (3). This formula holds when the decision maker chooses among the full set $\mathcal{L}_{0}$ or among a subset $\mathcal{L}_{i}$.

The modeler knows that the decision maker, having access to the information ex-ante, will select the same choice set and the same alternative as in a situation of selecting among the full set of alternatives; that is, if the decision maker were choosing in a single step. Consequently, when the decision maker has access to the information ex-ante, the choice probabilities computed by the modeler are the same as if the decision maker were choosing in a single step.

\subsection{No information, neither ex-ante nor ex-post}

In this no-information case, the decision maker knows the distributions of the individual terms, but ignores the realizations of these terms both before and after selecting the choice set. As the decision maker acquires no new information after selecting the choice set, the decision process amounts to a one-step procedure.

The no-information case can also be interpreted as a situation where the choice of the decision maker is the outcome of an embedded matching model. In this case, the decision maker devotes some effort to determine an opti- 
mal quality of matching. This quality determines the matching probabilities, defined as the probability that a given alternative is chosen by the decision maker. The necessary effort corresponds to minimizing the risk of unsatisfactory matching. The procedure yields the MNL probabilities:

$$
\mathbb{P}_{n}(i \mid \mathcal{L})=\frac{\exp \left(\frac{V_{n}(i)}{\mu}\right)}{\sum_{i^{\prime} \in \mathcal{L}} \exp \left(\frac{V_{n}\left(i^{\prime}\right)}{\mu}\right)}, i \in \mathcal{L}
$$

Eq. (13) holds when the decision maker chooses among the full set $\left(\mathcal{L}=\mathcal{L}_{0}\right)$ or among a nest $\left(\mathcal{L}=\mathcal{L}_{i}\right)$.

The probability that the decision maker is allocated to the nest $\mathcal{L}_{i}$ is the sum of the probabilities associated to each alternative in the nest $\mathcal{L}_{i}$ :

$$
\mathbb{P}_{n}\left(\mathcal{L}_{i} \mid \mathcal{L}_{0}\right)=\frac{\sum_{i^{\prime \prime} \in \mathcal{L}_{i}} \exp \left(\frac{V_{n}\left(i^{\prime \prime}\right)}{\mu}\right)}{\sum_{i^{\prime} \in \mathcal{L}_{0}} \exp \left(\frac{V_{n}\left(i^{\prime}\right)}{\mu}\right)}, \mathcal{L}_{i} \subset \mathcal{L}_{0}
$$

From Eq. (14), $\mathbb{P}_{n}\left(i \mid \mathcal{L}_{0}\right)=\mathbb{P}_{n}\left(i \mid \mathcal{L}_{i}\right) \mathbb{P}_{n}\left(\mathcal{L}_{i} \mid \mathcal{L}_{0}\right)$ : the probability that a decision maker choosing in two stages is allocated to a given alternative is the same as if the decision maker were choosing in a single step. The modeler, who has access to the same information as the decision maker, computes the same probability.

The case involving ex-ante information and no information ex-post is inconsistent because ex-ante information is included in ex-post information.

\subsection{One-step versus two-step decision process: MNL ver- sus nested logit}

To sum up, the decision is achieved in one step when information is the same ex-ante and ex-post, and in two steps when information is acquired ex-post (learning case). This latter case applies when alternatives are so many that the decision maker, unable to acquire information on all alternatives, selects 
a choice set in the first step from the ex-ante value of this choice set. In the second step, the decision maker acquires information about the alternatives contained in the choice set selected ex-ante in the first step (but not about alternatives included in other choice sets).

In the full-information case, the choice is deterministic for the decision maker, but probabilistic and given by the MNL in Eq. (3) for the modeler, who ignores the value of the individual terms.

In the no-information case, the choice is random both for the decision maker and for the modeler, and the choice probabilities are given by the same MNL in Eq. (3).

The fact that the modeler computes the same probability in the fullinformation and in the no-information cases implies that it is not possible to test one model against the other. The data contains no information that can be used to test whether the decision maker has full or no information.

On the contrary, the probability computed by the modeler is different in the learning case because the modeler knows that the decision maker will acquire information ex-post, even though the modeler acquires no information ex-post. In the learning case, the decision maker in the first step will certainly select the choice set that is the best ex-ante, maximizing the surplus computed as in Eq. (7). For the subset $\mathcal{L}_{i^{\prime}}$, the surplus is:

$$
S_{n}\left(\mathcal{L}_{i^{\prime}}\right) \equiv \mathbb{E} U_{n}\left(\mathcal{L}_{i^{\prime}}\right)=\mu_{1} \ln \left(\sum_{i^{\prime \prime} \in \mathcal{L}_{i^{\prime}}} \exp \left(\frac{V_{n}\left(i^{\prime \prime}\right)}{\mu_{1}}\right)\right)
$$

where $\mu_{1}$ is proportional to the standard deviation of the individual terms within $\mathcal{L}_{i^{\prime}}$.

The decision maker's preferences are assumed to reflect her perception of the quality of the subset. The corresponding individual terms are assumed to be i.i.d. Gumbel distributed with zero mean and standard deviation proportional to $\mu_{2}$. Using the same reasoning as before, the probability computed 
by the modeler that the decision maker selects the subset $\mathcal{L}_{i}, i=1, \ldots, I$ is:

$$
\mathbb{P}_{n}\left(\mathcal{L}_{i}\right)=\frac{\exp \left(\frac{S_{n}\left(\mathcal{L}_{i}\right)}{\mu_{2}}\right)}{\sum_{i^{\prime}=1}^{I} \exp \left(\frac{S_{n}\left(\mathcal{L}_{i^{\prime}}\right)}{\mu_{2}}\right)}, i=1, \ldots, I
$$

When $\mu_{1}=\mu_{2}$, the NL probabilities boil down to the MNL probabilities. The test of the equality $\mu_{1}=\mu_{2}$ amounts to testing that there is no acquisition of information from the first to the second decision stage.

We now consider a multi-level nested model, in which individuals decide upon their residential location, workplace, and type of employment, and may acquire information at each choice step. Each level in this nested model is described by a MNL model, so the full model is a multi-level NL model with different scale parameters, and a MNL model with equal scale parameters when no information is available.

\section{Data}

The model is estimated using exhaustive household data from the 1999 French census in the Île-de-France region. Type of employment and individual characteristics are observed for $100 \%$ of the population, corresponding to about 11 million inhabitants regrouped in 5 million households. Residential location and workplace are observed at the commune (municipality) level for a $5 \%$ sample of the working population, around 240,000 workers in 1999 . The commune is the smallest administrative unit used in France. The Paris region is composed of 1,300 communes, of which 20 form the city of Paris. The 1,300 communes are grouped into eight départements. The city of Paris counts about 2 million inhabitants. The inner ring (close suburbs) is made up of three départements, while the outer ring is composed of four départements (Figure 2 .

[Insert Figure 2] 
The area shows spatial disparities in the supply of employments. In particular, many outer ring communes have little or no employment supply. Almost $25 \%$ of the 1,300 communes (almost entirely located in the outer ring) are very small communes in terms of number of employments (Figure 3). In order to circumvent this problem, small adjacent communes were grouped into "pseudo-communes" following a simple pairwise aggregation (Babcock, 2010) until each pseudo-commune contained at least 100 employments. The resulting 950 pseudo-communes with 100 employments or more were used as units of location for both employments and residence.

\section{[Insert Figure 3}

The census data was aggregated at the pseudo-commune level, and variables measuring prices and local amenities were computed at the same level. Price data come from the Cote Callon annual real estate market price assessment (La cote annuelle des valeurs vénales immobilières et foncières 1999), which reports average prices per $m^{2}$ for offices and dwellings by type and tenure status for communes with more than 5,000 inhabitants (287 communes, each of them containing at least 100 employments). We estimated hedonic price regressions jointly for each tenure and dwelling type as well as for offices, and used the results to predict prices in smaller pseudo-communes. Palma et al. (2007) describe local amenities, price equations, and the method used for correcting the endogeneity of prices.

We estimated origin-destination (O-D) matrices of travel time for public transportation from the Regional department of infrastructure and transportation planning (DRIEA) transport model MODUS. We computed O-D matrices of travel time for private cars using the dynamic transport network model METROPOLIS described in Palma et al. (1997). The transport model METROPOLIS has a dynamic traffic simulator where vehicles are simulated individually and traffic dynamics are modeled at the aggregate level. The 
disaggregate representation of demand allows us to consider the heterogeneity of the population and trips. Saifuzzaman et al. (2012) provide detailed information on the calibration of METROPOLIS for the Paris region.

The sample contains 239,499 people living and working in Île-de-France. We estimated the lowest and intermediate level models (choice of type of employment and of workplace) separately in 24 subsamples in order to reflect how individual preferences and employment opportunities depend on age, education, sex, and fertility. The sample is split in two age groups of approximately equal size, those under 35 and those over 35 . We defined education groups (elementary, secondary, undergraduate, and graduate) according to preliminary results measuring the influence of education on the choice of the type of employment. Similarly, we measured the influence of fertility on the choice of the type of employment of women by a dummy variable indicating whether or not a woman has at least one child under 12. The combination of education, age, sex, and fertility categories yields 24 categories (Table 2).

[Insert Table 2

\section{A nested logit model for type of employment, work- place, and residential location}

The individual $n$ chooses a residential location $i$, a workplace $j$, and a specific employment $l$ of type $k$ in a set denoted by $\mathcal{E}_{n}$. There are $I$ locations and $K$ types of employment. Individual utility, denoted by $U_{n}$, is:

$$
U_{n}(l, k, j, i)=U_{n}^{T}(l, k)+U_{n}^{W}(j)-C_{n}^{W R}(j, i)+U_{n}^{R}(i) \quad \forall(l, k, j, i) \in \mathcal{E}_{n},
$$

where $U_{n}^{T}(l, k)$ denotes the utility specific to employment $l$ of type $k, U_{n}^{W}(j)$ the utility specific to the workplace $j$, and $U_{n}^{R}(i)$ the utility of living in residential location $i$. The term $C_{n}^{W R}(j, i)$ captures the total commuting cost between residential location $i$ and workplace $j$. 
The model is focused on the selection of a specific employment, including its type and location, and on the choice of a residential location. We solve a three-stage model by backward induction (Figure 1). At the lowest level, the individual $n$ chooses a specific employment $l$ of type $k$, conditional on workplace $j$ and residential location $i$. At the intermediate level, the individual $n$ chooses a workplace $j$, conditional on residential location $i$ and anticipating an employment $l$ of type $k$. At the highest level, the individual $n$ chooses a residential location $i$, anticipating the work-related choices $(j, k, l)$.

\section{[Insert Figure 1]}

We impose additive separability between the deterministic and stochastic components of the utility at each level. The utility $U_{n}^{T}(l, k)$ provided by the employment $l$ of type $k$, in Eq. (17), is decomposed into a deterministic term $V_{n}^{T}(k)$ depending on type $k$, a random term $\varepsilon_{n}^{0}(l)$ depending on the employment $l$, and a random term $\varepsilon_{n}^{1}(k)$ depending on type $k$. The deterministic term $V_{n}^{T}(k)$ represents the preferences of individual $n$ for employment type $k$. A deterministic term specific to the utility of performing a specific employment $l$ would be added if employment characteristics could be observed. This would add a level to the tree. Under full information, the preference of individual $n$ is represented by the random term $\varepsilon_{n}^{0}(l)$ for the specific employment $l$, and by the random term $\varepsilon_{n}^{1}(k)$ for the employment type $k$. In the no-information and learning cases, these random terms rather represent employment-specific and type-specific characteristics unknown by the decision maker before choosing the workplace and the employment type. In the learning case, after selecting the employment type $k$, the decision maker acquires information about the realization of $\varepsilon_{n}^{0}(l)$ for all employments of type $l$ located in $j$.

$V_{n}^{W}(j)$ measures the intrinsic preference for working in $j$ and $V_{n}^{R}(i)$ the intrinsic preference for living in $i$. Both are deterministic. The choices of residential location and workplace are related to one another through the total commuting cost $C_{n}^{W R}(j, i)$. Under full information, the random terms $\varepsilon_{n}^{2}(j)$ 
and $\varepsilon_{n}^{3}(i)$ correspond to the preference (leading to the unobserved heterogeneity of preferences) of individual $n$ for working in $j$ and living in $i$. An additional random term representing the total commuting cost would be impossible to disentangle from $\varepsilon_{n}^{2}(j)$. That is why $\varepsilon_{n}^{2}(j)$ also includes the preference for commuting between $i$ and $j$. In the no information case, $\varepsilon_{n}^{2}(j)$ and $\varepsilon_{n}^{3}(i)$ represent local characteristics remaining unknown by the decision maker. In the learning case, $\varepsilon_{n}^{2}(j)$ and $\varepsilon_{n}^{3}(i)$ also represent local characteristics available to the decision maker. The decision maker observes $\varepsilon_{n}^{3}(i)$ at the first stage, but acquires information about $\varepsilon_{n}^{2}(j)$ only after selecting residential location $i$ (which is plausible for commuting costs).

The random terms $\varepsilon_{n}^{\iota}(\cdot), \iota=i, j, k, l$, are independent for a given individual $n$ and independent across individuals.

Utility $U_{n}(l, k, j, i)$ is decomposed as:

$$
\begin{aligned}
U_{n}(l, k, j, i)=V_{n}^{T}(k)+ & \varepsilon_{n}^{0}(l)+\varepsilon_{n}^{1}(k)+V_{n}^{W}(j)-C_{n}^{W R}(j, i)+\varepsilon_{n}^{2}(j) \\
& +V_{n}^{R}(i)+\varepsilon_{n}^{3}(i) ; \quad \forall(l, k, j, i) \in \mathcal{E}_{n} .
\end{aligned}
$$

\subsection{Lowest level choice: specific employment and type of employment}

The additive separability assumed in Eq. 18 means that the preference of individual $n$ for a specific employment $l$ of type $k$ is independent from the employment location. This preference may be related, for example, to wages, or to the total number of working hours. These characteristics vary across employment types, depending on individual characteristics such as sex, education, or age. This is the reason why $V_{n}^{T}(k), \varepsilon_{n}^{0}(l)$, and $\varepsilon_{n}^{1}(k)$ are indexed by $n$. We assume that the difference between the utilities of two employment types for a given individual is independent of location. For this reason $V_{n}^{T}(k)+\varepsilon_{n}^{0}(l)+\varepsilon_{n}^{1}(k)$ does not depend on employment and residential locations $i$ and $j$. This does not exclude that employment characteristics vary 
geographically. For example, wages may be systematically higher in a location $j$ than in a location $j^{\prime}$. These geographical differences, if any, can be included in $V_{n}^{W}(j)+\varepsilon_{n}^{2}(j)$, provided they are the same across types of employment. We exclude the case where geographical differences are specific to a type of employment, for example, where wages are systematically higher in $j$ then in $j^{\prime}$ for blue collar jobs, but identical in $j$ and $j^{\prime}$ for white collar jobs. This interpretation in the full-information case, also applies in the learning and no information cases. As a result, the choice between the various employments located in $j$ only depends on individual characteristics and employment types, and is not affected by local observed or unobserved characteristics of workplace or residential location.

$\mathcal{T}_{k j}$ denotes the set of employments of type $k$ available to an individual $n$ in location $j$, with $\left|\mathcal{T}_{k j}\right|=N_{k j}$. Because the deterministic part of the utility $V_{n}^{T}(k)$ depends only on employment type $k$, but not on the specific employment $l$, all the employments in $\mathcal{T}_{k j}$ have the same probability $1 / N_{k j}$ to be selected, and Eq. 10 implies that the expected value of employment type $k$ in location $j$ is

$$
\mathbb{E} U_{n}\left(\mathcal{T}_{k j}\right)=V_{n}^{T}(k)+\mu^{0} \log \left(N_{k j}\right)
$$

where $\mu^{0}$ denotes the scaling factor of $\varepsilon_{n}^{0}(l)$.

The probability that individual $n$ chooses employment type $k$ given workplace $j$ is then equal to

$$
\mathbb{P}_{n}^{1}(k)=\frac{\exp \left(\frac{V_{n}^{T}(k)+\mu^{0} \ln \left(N_{k j}\right)}{\mu^{1}}\right)}{\sum_{k^{\prime}=1, \ldots, K ; N_{k^{\prime} j}>0} \exp \left(\frac{V_{n}^{T}\left(k^{\prime}\right)+\mu^{0} \ln \left(N_{k^{\prime} j}\right)}{\mu^{1}}\right)}, \forall k=1, \ldots, K ; N_{k j}>0,
$$

where $\mu^{1}$ denotes the scaling factor of $\max _{l \in \mathcal{T}} \varepsilon_{n}^{0}(l)+\varepsilon_{n}^{1}(k)$, which is assumed to follow a Gumbel distribution in the learning case. The ratio $\frac{\mu^{0}}{\mu^{1}}$ then corresponds to the ratio of the standard error of individual preferences at the employment-specific level and at the employment-type level, that is the rel- 
ative intensity of unobserved preferences between employments of the same type and between types of employment.

In the two other cases (full-information and no-information), $\mu^{0}=\mu^{1}$, and the coefficient of $\ln \left(N_{k j}\right)$ simplifies to 1 . Indeed, when the decision maker acquires no information after choosing her nest (here type of employment), her choice probabilities are the same as if she were choosing in one step in the full choice set, and given by the MNL formula. In this case, the probability of specific employment $l$ is given by

$$
\mathbb{P}_{n}^{0}(l, k)=\frac{\exp \left(\frac{V_{n}^{T}(k)}{\mu^{1}}\right)}{\sum_{k^{\prime}=1, \ldots, K, N_{k^{\prime} j}>0}\left(\sum_{l \in \mathcal{T}_{k^{\prime} j}} \exp \left(\frac{V_{n}^{T}\left(k^{\prime}\right)}{\mu^{1}}\right)\right)},
$$

and the choice probability of employment type $k$ given workplace $j$ is equal to

$$
\begin{aligned}
\mathbb{P}_{n}^{1}(k) & =\sum_{l \in \mathcal{T}_{k^{\prime} j}} \frac{\exp \left(\frac{V_{n}^{T}(k)}{\mu^{1}}\right)}{\sum_{k^{\prime}=1, \ldots, K, N_{k^{\prime} j}>0}\left(\sum_{l \in \mathcal{T}_{k^{\prime} j}} \exp \left(\frac{V_{n}^{T}\left(k^{\prime}\right)}{\mu^{1}}\right)\right)} \\
& =\frac{N_{k j} \exp \left(\frac{V_{n}^{T}(k)}{\mu^{1}}\right)}{\sum_{k^{\prime}=1, \ldots, K, N_{k^{\prime} j}>0}\left(N_{k^{\prime} j} \exp \left(\frac{V_{n}^{T}\left(k^{\prime}\right)}{\mu^{1}}\right)\right)} \\
& =\frac{\exp _{n}\left(\frac{V_{n}^{T}(k)+\mu^{1} \ln \left(N_{k j}\right)}{\mu^{1}}\right)}{\sum_{k^{\prime}=1, \ldots, K, N_{k^{\prime} j}>0}\left(\exp \left(\frac{V_{n}^{T}\left(k^{\prime}\right)+\mu^{1} \ln \left(N_{k^{\prime} j}\right)}{\mu^{1}}\right)\right)} .
\end{aligned}
$$

Allowing $\mu^{0} / \mu^{1}$ to vary across individual types (denoted by $\mu_{n}^{0} / \mu_{n}^{1}$ ) amounts to considering that the relative intensity of unobserved preferences between employments of the same type and between types of employment varies across 
individuals. The probability in Eq. 22 becomes:

$$
\mathbb{P}_{n}^{1}(k)=\frac{\exp \left(\delta_{n}^{1}+\delta_{n}^{0} \ln \left(N_{k j}\right)\right)}{\sum_{k^{\prime}=1, \ldots, K, N_{k^{\prime} j>0}} \exp \left(\delta_{n}^{1}+\delta_{n}^{0} \ln \left(N_{k^{\prime} j}\right)\right)},
$$

with $\delta_{n}^{0}=\frac{\mu_{n}^{0}}{\mu_{n}^{1}}$ and $\delta_{n}^{1}=\frac{V_{n}^{T}(k)}{\mu_{n}^{1}}$.

The choices of employment type $k$ and employment location $j$ are related only through the number $N_{k j}$ of employments of type $k$ in location $j$, denoted by $N_{k j}$. This comes from the assumption of additive separability in the utility function of Eq. (18).

In the case of the choice of type of employment conditional on workplace, the surplus in Eq. (15), which is the expected utility resulting from the choice of the best type of employment conditional on workplace $j$, is denoted by $S_{n}(j)$, and equal to:

$$
\begin{aligned}
S_{n}(j) & =\mu_{n}^{1} \ln \left(\sum_{k=1, \ldots, K ; N_{k j}>0}^{K} \exp \left(\frac{V_{n}^{T}(k)+\mu^{0} \ln \left(N_{k j}\right)}{\mu^{1}}\right)\right) \\
& =\mu_{n}^{1} \ln \left(\sum_{k=1, \ldots, K ; N_{k j}>0}^{K} \exp \left(\delta_{n}^{1}+\delta_{n}^{0} \ln \left(N_{k j}\right)\right)\right) .
\end{aligned}
$$

It measures the attractiveness of workplace $j$.

\subsection{Intermediate level choice: workplace location}

$\mathcal{I}$ denotes the set of all potential (residential or workplace) locations, with $|\mathcal{I}|=I$. These locations are assumed to be available for each individual both for working and for living, so $(i, j) \in \mathcal{I}^{2}$. With the decision tree assumed here, an individual $n$ chooses a workplace $j$ conditional on her current residential location $i$. Actual travel time is relevant for explaining workplace location through the generalized travel cost $C_{n}^{W R}(j, i)$.

From Eq. (17), the utility of workplace location $j$, including generalized 
commuting cost $C_{n}^{W R}(j, i)$, between residential location $i$ and workplace $j$, is:

$$
U_{n}^{W}(j)-C_{n}^{W R}(j, i)=V_{n}^{W}(j)-C_{n}^{W R}(j, i)+\varepsilon_{n}^{2}(j) \quad \forall j \in \mathcal{I} .
$$

Similarly to the lowest level in the full information case, the error term $\varepsilon_{n}^{2}(j)$ representing the unobserved heterogeneity preference of individual $n$ assignable to workplace $j$ is distributed in such a way that the random part of $\max _{(k, l)} U_{n}^{T}(l, k)+\varepsilon_{n}^{2}(j)$ has a Gumbel distribution with scale parameter $\mu_{n}^{2}$ specific to individual $n$ (Eq. (22)). The probability of choosing workplace location $j$ is then:

$$
\mathbb{P}_{n}^{2}(j)=\frac{\exp \left(\frac{V_{n}^{W}(j ;)-C_{n}^{W R}(j, i)+S_{n}(j)}{\mu_{n}^{2}}\right)}{\sum_{j^{\prime} \in \mathcal{I}} \exp \left(\frac{V_{n}^{W}\left(j^{\prime}\right)-C_{n}^{W R}\left(j^{\prime}, i\right)+S_{n}\left(j^{\prime}\right)}{\mu_{n}^{2}}\right)}, \quad \forall j \in \mathcal{I} .
$$

In the case of workplace choice conditional on residential location, the surplus in Eq. (15), which is the expected utility resulting from the choice of the best workplace conditional on residential location $i$, is denoted by $L S_{n}(i)$, and equal to:

$$
L S_{n}(i)=\mu_{n}^{2} \ln \left(\sum_{j \in \mathcal{I}} \exp \left(\frac{V_{n}^{W}(j)-C_{n}^{W R}(j, i)+S_{n}(j)}{\mu_{n}^{2}}\right)\right)
$$

It measures the accessibility of residential location $i$ to employments.

\subsection{Highest level: residential location}

In the highest level of the decision tree, the individual anticipates the choices of workplace, type of employment, and specific employment when she chooses her residential location. The utility of living in residential location $i$ (Eq. (17)) is:

$$
U_{n}^{R}(i)=V_{n}^{R}\left(i ; X_{n}, Z_{i}\right)+\varepsilon_{n}^{3}(i), \quad \forall i \in \mathcal{I} .
$$


The residual term $\varepsilon_{n}^{3}(i)$ accounts for the unobserved heterogeneity preference of individual $n$ for residential location $i$. It expresses unobserved location characteristics, variation in individual tastes, and model misspecification. Similarly to other levels, this residual term is distributed so that the random part of $\max _{(j, k, l)} U_{n}^{T}(l, k)+U_{n}^{W}(j)-C_{n}^{W R}(j, i)+\varepsilon_{n}^{3}(i)$ is type I extreme value distributed with scale parameter $\mu_{n}^{3}$. The probability of choosing residential location $i$ is then:

$$
\mathbb{P}_{n}^{3}(j)=\frac{\exp \left(\frac{V_{n}^{R}\left(i ; X_{n}, Z_{i}\right)+L S_{n}(i)}{\mu^{3}}\right)}{\sum_{i^{\prime} \in \mathcal{I}} \exp \left(\frac{V_{n}^{R}\left(i^{\prime} ; X_{n}, Z_{i^{\prime}}\right)+L S_{n}\left(i^{\prime}\right)}{\mu^{3}}\right)}, \quad \forall i \in \mathcal{I} .
$$

\subsection{Method}

The nested logit is estimated sequentially by backward induction: the first model corresponds to the choice of type of employment, the second to the choice of workplace, and the third to the choice of residential location. A multinomial logit (MNL) model is estimated at each level, including a logsum variable at the intermediate and highest levels.

The difficulty of the large number of alternatives (950 pseudo-communes) is overcome by using random sampling, which consists in randomly selecting a small number of alternatives for each individual, with equal probabilities of selection in the choice set. McFadden (1978) showed that random sampling leads to consistent estimates of the coefficients of a MNL model under the IIA assumption. Ben-Akiva et al. (1985) showed that importance sampling, consisting in increasing the probability that a given alternative is included in the choice set improves the efficiency of estimates, and usually induces a bias in the coefficients, which is to be corrected. In our case, the probability that a pseudo-commune is included in the choice set is proportional to the total number of dwellings (highest level) or of employments (intermediate level) in that pseudo-commune. In the absence of information, all dwellings of the same 
type and tenure status located in the same pseudo-commune are statistically identical and provide the same expected utility and the same odds of being selected by a household. Similarly, in the absence of information, all employments of the same type located in the same pseudo-commune are statistically identical. The importance sampling of pseudo-communes considered here is equivalent to uniform random sampling of dwellings (or employments), so the coefficients are not biased and no correction is necessary.

The strong segmentation of the dwelling market in France implies that prices vary across dwelling types and tenure status, so it is relevant to consider dwelling prices specific to each of the four sub-markets. Moreover, at a given point in the life cycle, a given household is usually not flexible concerning dwelling type and tenure status. This adds a level at the top of the tree (Figure 4). Residential location is estimated separately in the four sub-samples defined by dwelling type and tenure status, which amounts to assuming that dwelling type and tenure status is exogenous to the choice of residential location.

$$
\text { [Insert Figure 4] }
$$

The choice of residential location is restricted to one-worker households, in order to avoid the bargaining considerations that would arise in a multipleworker household. In such households, the employments of the different workers are usually located in different places, and each household member has to bargain so that the household finds a residence closer to his/her employment.

\section{Results}

\subsection{Choice of type of employment}

Twenty-four multinomial logit (MNL) models are estimated for the choice between type of employments: blue collar, employee, intermediate, manager, and independent. Given the small number of alternatives (5 employment types), no random sampling is necessary at this level. 
Table 3 shows the results of the MNL model of employment type. Almost all estimated coefficients by type of employment are significant. The measure of goodness of fit presented in the last column of Table 3 shows that the explanatory power increases with men's education. Less educated men accept any employment and are randomly assigned to employment types such as blue collar, employee, or independent. By contrast, the most educated men accept only employment types best suited to them (manager, intermediate, and independent). For women, depending on age and fertility, the most influential factor in deciding whether or not to work for a woman is education, rather than the choice of employment type.

\section{[Insert Table 3}

The log-sum corresponds to the sum of the log-number of employments by type, weighted by the individual-specific probability to choose a particular type of employment. This individual-specific measure of attractiveness, defined in Eq. (24), varies between employment locations and between individual characteristics. The attractiveness of the employment type of each workplace, computed as the log-sum across local employment types, is represented in Figures 5, 6, and 7 by sex and education.

$$
\text { [Insert Figures 5, 6, and 7] }
$$

\subsection{Choice of workplace location}

The only criteria involved in choosing a workplace location considered here are the generalized commuting $\operatorname{cost} C_{n}^{W R}(j, i)$ and the availability of employments of different types found in the inclusive value or surplus term $S_{n}(j)$. Waddell (1993) included average wage by employment type as an explanatory variable of workplace location choice. Any significant difference in wages between locations in our geographical units is already in the employment type surplus term $S_{n}(j)$, because this term allows us to account for differences in the employment structure between different workplace locations. With the purpose 
of constructing a parsimonious workplace choice model, the $V_{n}^{W}\left(j ; X_{n}, Z_{j}\right)$ term is considered nil.

The workplace location choice of a pseudo-commune is considered to depend on its attractiveness of employment type (the individual-specific measure computed in the employment type choice model) and the commuting travel time of individuals. The results of the 24 workplace location choice models are presented in Table 4.

[Insert Table 4]

In the column labeled "attractiveness" of Table 4 , the estimated coefficients indicate that the more educated and older men are more attracted by the types of employment than younger and less educated. Women are less attracted than men to the types of employment.

Columns labeled "travel time" and "(travel time) $)^{2 "}$ suggest that the utility of workplace location decreases and is concave in travel time for each of the 24 groups. The value of time then depends on age, education, sex, and children.

We estimated the 24 workplace location choice models using the log number of employments. The last column of Table 4 presents the difference between the likelihood ratio (LR) of the workplace location choice model estimated with the attractiveness measure and the LR of the models estimated with the size measure. The measure of attractiveness (specific to each individual) is a better predictor of the workplace location choice than the commonly used log total number of employments.

The log-sum of workplace locations is an appropriate accessibility measure specific to each individual which is also the expected maximum utility of all employment opportunities. This measure varies with residence and individual characteristics. Accessibility differs across groups because the local employment prospects and the value of time differ across them. The measure of accessibility to employments is mapped in Figures 8 and 10 by sex and 
education. The higher an individual is educated, the wider are the differences in accessibility (Figure 10).

[Insert Figures 8 and 10 ]

\subsection{Choice of residential location}

Tables 6 and 7 concern households with only one worker. In households with more than one worker, negotiation among spouses modifies the choice of residential location and workplace. The location model is estimated separately by tenure type (owner and tenant) and dwelling type (apartment and single dwelling). Sample sizes by tenure and dwelling type are presented in Table 5

[Insert Table 5]

The last rows of Tables 6 and 7 present the goodness of fit, which is higher for owners than for renters. This is consistent with the fact that purchasing decisions are less random than renting decisions. The goodness of fit is higher for the choice of single dwellings than for the choice of apartments, which is consistent with the housing turnover rates, higher for renters than for owners, and higher for apartments than for single dwellings. Location decisions are more thoughtful for the longer term.

[Insert Table 6]

Owners are more sensitive to accessibility than tenants; households living in apartments are more sensitive to accessibility than those living in a single dwelling. These results are consistent with considerations of life cycle and geographical distribution of single dwellings and apartments. In early stages of the life cycle, when households have no children yet, they usually rent an apartment located in relation to potential employments. At later stages of the life cycle, households buy single dwellings far away in the suburbs. Subways and suburban train stations attract only households who rent apartments. 
Table 6 shows that for households with an average income, the price has a negative effect on the probability of location, with the exception of households renting a single dwelling (small sample). The negative effect of price decreases with income, and may be positive for the richest households.

Net all other effects, people in the outer ring prefer a single dwelling to an apartment. Apartments located in a now town are preferred. Single dwellings are chosen with the same preference in planned cities or in other locations (net all other effects). The effect of the residence tax for ownership and tenancy and property taxes for ownership is ambiguous. Higher taxes have a direct negative effect, but they are usually associated with local services such as child care center or streets amenities, not measured here.

\section{[Insert Table 7}

In Table 7, as expected, households living in an apartment are more likely to move to a dense area, and those living in a single dwelling are less likely to do so. Similarly, households renting are more likely to move to a dense area, and those living in their own dwelling are less likely to do so. Households join households with similar age, size, and income. Single dwelling owners are more attracted by communes with a high percentage of foreigners, because (rich) foreigners who settle in the Paris region tend to buy dwellings close to their compatriots. Beyond a certain threshold, the percentage of (poorer) foreigners can be deterrent, but the concerned communes include few dwelling-owners. Renters are attracted by the percentage of foreigners but this decreases with education.

\section{Conclusion}

Micro-simulation models of urban land use ignore the association of residential location, workplace, and decision for employment type. Urban models of general equilibrium consider only limited heterogeneity. Heterogeneity may affect several aspects of urban models such as travel behavior (see Xin et al. (2013) in 
this issue and Coulombel et al. (2013) in a companion issue. In other to breach this gap, a three-level nested logit model for the choices of residential location, workplace, and type of employment allowed us to compute individual-specific measures of accessibility to employments, value of time, and attractiveness to the type of employments. We took into account the individual-specific attractiveness to the type of employments and the heterogeneity of preferences with respect to education, age, sex, and fertility.

The measure of attractiveness to type of employments is a better predictor of workplace than the usual measure of total number of employments. Workers are not attracted indifferently by any employment, but by the employments which are better suited to them. This is stronger for highly educated men. Individual-specific accessibility determines the choice of residential location choice, and its effects vary along the life cycle. 


\section{References}

Abraham, J. E. and Hunt, J. D. (1997). Specification and estimation of nested logit model of home, workplaces, and commuter mode choices by multipleworker households. Transportation Research Record, 1606: 17-24.

Alonso, W. (1964). Location and Land Use: Toward a General Theory of Land Rent. Cambridge, Massachusetts: Harvard University Press.

Anas, A. (1981). The estimation of multinomial logit models of joint location and travel mode choice from aggregated data. Journal of Regional Science, $21(2): 223-242$.

Anderson, S., Palma, A. d., and Thisse, J.-F. (1992). Discrete Choice Theory of Product Differentiation. Cambridge, Massachusetts: the MIT Press.

Babcock, G. (2010). Aggregation without aggravation: determining spatial contiguity and joining geographic areas using hashing. Seattle, Washington: Proceedings of the SAS Global Forum.

Ben-Akiva, M. and Lerman, S. R. (1985). Discrete Choice Analysis: Theory and Application to Travel Demand. Cambridge, Massachusetts: the MIT Press.

Ben-Akiva, M. and Bowman, J. L. (1998). Integration of an activity-based model system and a residential location model. Urban Studies, 35(7): $1131-1153$.

Ben-Akiva, M., Palma, A., McFadden, D., et al. (2012). Process and context in choice models. Marketing Letters, 22(2): 439-456.

Bhat, C. R. and Guo, J. (2004). A mixed spatially correlated logit model: formulation and application to residential choice modeling. Transportation Research Part B: Methodological, 38(2): 147-168.

Clark, W. and Davies, S. (1999). Changing jobs and changing houses: Mobility outcomes of employment transitions. Journal of Regional Science, 39(4): 653-673. 
Cohen, M. (2013). Risk perception, risk attitude, and decision: a rank-dependent analysis. Mathematical Population Studies.

Coulombel, N. and Palma, A. de (2013). The variability of travel time, congestion, and the cost of travel. Mathematical Population Studies.

Crane, R. (1996). The influence of uncertain job location on urban form and the journey to work. Journal of Urban Economics, 39(3): 342 -356.

Eliasson, J. and Mattsson, L.-G. (2000). A model for integrated analysis of household location and travel choices. Transportation Research Part A: Policy and Practice, 34(5): 375-394.

Freedman, O. and Kern, C. R. (1997). A model of workplace and residence choice in two-worker households. Regional Science and Urban Economics, $27(3): 241-260$.

Kan, K. (1999). Expected and unexpected residential mobility. Journal of Urban Economics, 45(1): 72-96.

Kan, K. (2002). Residential mobility with job location uncertainty. Journal of Urban Economics, 52(3): 501-523.

La cote annuelle des valeurs vénales immobilières et foncières (1999). Surgères: Éditions Callon.

Lee, B. and Waddell, P. (2010). Residential mobility and location choice: a nested logit model with sampling of alternatives. Transportation, 37(4): $587-601$.

Lerman, S. R. (1976). Location, housing, automobile ownership, and mode to work: A joint choice model. Transportation Research Record, 610: 6-11.

Levine, J. (1998). Rethinking Accessibility and Jobs-Housing Balance. Journal of the American Planning Association, 64(2): 133-149.

Levinson, D. M. (1998). Accessibility and the Journey to Work. Working Papers 199802. University of Minnesota: Nexus Research Group.

Linneman, P. and Graves, P. E. (1983). Migration and job change: A multinomial logit approach. Journal of Urban Economics, 14(3): 263-279. 
Manski, C. F. and Lerman, S. R. (1977). The Estimation of Choice Probabilities from Choice Based Samples. Econometrica, 45(8): 1977-1988.

McFadden, D (1978). Modeling the residential location. Transportation Research Record, 673: 72-77.

Mills, E. S. (1972). Studies in the Structure of the Urban Economy. Baltimore, Maryland: The Johns Hopkins Press.

Muth, R. F. (1969). Cities and Housing: The Spatial Pattern of Urban Residential Land Use. Chicago, Illinois: University of Chicago Press.

Palma, A. d., Marchal, F., and Nesterov, Y. (1997). METROPOLIS : A modular architecture for dynamic traffic simulation. Transportation Research Record, 160\%: 178-184.

Palma, A. d., Motamedi, K., Picard, N., et al. (2007). Accessibility and environmental quality: Inequality in the paris housing market. European Transport, 36: 47-74.

Palma, A. d., Ben-Akiva, M., Brownstone, D., et al. (2008). Risk, uncertainty and discrete choice models. Marketing Letters, 19(3): 269-285.

Saifuzzaman, M., Palma, A. d., and Motamedi, K. (2012). Calibration of METROPOLIS for Ile de-France. SustainCity Working Paper, 7.2. ENSCachan.

Sermons, M. and Koppelman, F. S. (2001). Representing the differences between female and male commute behavior in residential location choice models. Journal of Transport Geography, 9(2): 101-110.

Siegel, J. (1975). Intrametropolitan migration: A simultaneous model of employment and residential location of white and black households. Journal of Urban Economics, 2(1): 29-47.

Simpson, W. (1980). A simultaneous model of workplace and residential location incorporating job search. Journal of Urban Economics, 8(3): 330349. 
Thurstone, L. (1927). A law of comparative judgement. Psychological Review, 34: $273-286$.

Waddell, P. (1993). Exogenous workplace choice in residential location models: Is the assumption valid? Geographical Analysis, 25(1): 65-82.

Waddell, P., Bhat, C., Eluru, N., et al. (2007). Modeling interdependence in household residence and workplace choices. Transportation Research Record, 200\%: 84-92.

Xin, W. and Levinson, D. (2013). A Stochastic congestion and pricing model with endogenous departure time selection and heterogeneous travelers. Mathematical Population Studies. 
Table 1. Examples of chosen alternatives under the full information and learning cases

\begin{tabular}{cccccc}
\hline & & Expected utility & Realization & Utility & \\
Choice set & Alternative & $V_{i}$ & $e_{i}$ & $U_{i}$ & Chosen alternative \\
\hline 1 & 1 & 0 & 2 & 2 & under full information \\
1 & 2 & 0 & 1 & 1 & \\
2 & 3 & 1 & 0 & 1 & in the learning case \\
2 & 4 & 1 & -1 & 0 & \\
\hline
\end{tabular}


Table 2. Sample size per category

\begin{tabular}{|c|c|c|c|c|c|c|}
\hline \multirow[b]{4}{*}{ Education } & \multicolumn{2}{|c|}{ Men } & \multicolumn{4}{|c|}{ Women } \\
\hline & \multirow[t]{3}{*}{ Under 35} & \multirow[t]{3}{*}{35 and over } & \multicolumn{2}{|c|}{ Under 35} & \multicolumn{2}{|c|}{35 and over } \\
\hline & & & With & Without & With & Without \\
\hline & & & children & children & children & children \\
\hline Elementary & 18,270 & 36,813 & 5,002 & 7,700 & 5,974 & 25,577 \\
\hline Secondary & 8,551 & 12,750 & 2,950 & 5,883 & 3,402 & 11,251 \\
\hline Undergraduate & 10,441 & 10,234 & 3,354 & 9,569 & 3,145 & 7,791 \\
\hline Graduate & 11,091 & 17,279 & 2,478 & 8,549 & 3,165 & 8,280 \\
\hline
\end{tabular}

Note: Total sample size of 239,499 working people. Categorization by sex, age, children, and education resulted in 24 sub-samples. A woman is categorized as having children if she has at least one child of 11 years old or less. Source: general population census for Île-de-France. Insee, 1999. 
Table 3. Choice of type of employment

\begin{tabular}{|c|c|c|c|c|c|c|}
\hline \multirow[b]{2}{*}{ Groups } & \multirow[b]{2}{*}{$\ln N_{j k}$} & \multicolumn{4}{|c|}{ Employment type preferences (reference: blue collar) } & \multirow[b]{2}{*}{$\mathrm{LRI}^{\dagger}$} \\
\hline & & Independent & Managerial & Intermediate & Employee & \\
\hline \multicolumn{7}{|l|}{ Men } \\
\hline \multicolumn{7}{|l|}{ Under 35} \\
\hline Elementary & $\begin{array}{l}0.82^{* *} \\
(0.02)\end{array}$ & $\begin{array}{c}-1.53^{* *} \\
(0.04)\end{array}$ & $\begin{array}{l}-3.25^{* *} \\
(0.05)\end{array}$ & $\begin{array}{c}-1.71^{* *} \\
(0.02)\end{array}$ & $\begin{array}{c}-1.36^{* *} \\
(0.02)\end{array}$ & 0.30 \\
\hline Secondary & $\begin{array}{l}0.86^{* *} \\
(0.04)\end{array}$ & $\begin{array}{c}-0.94^{* *} \\
(0.07)\end{array}$ & $\begin{array}{c}-1.70^{* *} \\
(0.05)\end{array}$ & $\begin{array}{c}-0.39^{* *} \\
(0.03)\end{array}$ & $\begin{array}{c}-0.36^{* *} \\
(0.03)\end{array}$ & 0.16 \\
\hline Undergraduate & $\begin{array}{l}0.96^{* *} \\
(0.04)\end{array}$ & $\begin{array}{l}0.03^{* *} \\
(0.08)\end{array}$ & $\begin{array}{l}0.25^{* *} \\
(0.04)\end{array}$ & $\begin{array}{l}1.26^{* *} \\
(0.04)\end{array}$ & $\begin{array}{l}0.43^{* *} \\
(0.04)\end{array}$ & 0.21 \\
\hline Graduate & $\begin{array}{l}0.83^{* *} \\
(0.04)\end{array}$ & $\begin{array}{l}0.91^{* *} \\
(0.10)\end{array}$ & $\begin{array}{l}2.96^{* *} \\
(0.06)\end{array}$ & $\begin{array}{l}1.59^{* *} \\
(0.07)\end{array}$ & $\begin{array}{l}0.50^{* *} \\
(0.07)\end{array}$ & 0.44 \\
\hline \multicolumn{7}{|l|}{35 and over } \\
\hline Elementary & $\begin{array}{l}0.81^{* *} \\
(0.01)\end{array}$ & $\begin{array}{l}-0.33^{* *} \\
(0.02)\end{array}$ & $\begin{array}{c}-1.95^{* *} \\
(0.02)\end{array}$ & $\begin{array}{l}-1.01^{* *} \\
(0.01)\end{array}$ & $\begin{array}{l}-1.33^{* *} \\
(0.01)\end{array}$ & 0.13 \\
\hline Secondary & $\begin{array}{l}0.80^{* *} \\
(0.03)\end{array}$ & $\begin{array}{l}0.70^{* *} \\
(0.048)\end{array}$ & $\begin{array}{l}0.30^{* *} \\
(0.03)\end{array}$ & $\begin{array}{l}0.46^{* *} \\
(0.03)\end{array}$ & $\begin{array}{l}-0.35^{* *} \\
(0.03)\end{array}$ & 0.07 \\
\hline Undergraduate & $\begin{array}{l}0.74^{* *} \\
(0.03)\end{array}$ & $\begin{array}{l}1.20^{* *} \\
(0.06)\end{array}$ & $\begin{array}{l}1.54^{* *} \\
(0.04)\end{array}$ & $\begin{array}{l}1.30^{* *} \\
(0.04)\end{array}$ & $\begin{array}{l}-0.30^{* *} \\
(0.05)\end{array}$ & 0.19 \\
\hline Graduate & $\begin{array}{l}0.60^{* *} \\
(0.03)\end{array}$ & $\begin{array}{l}1.88^{* *} \\
(0.06)\end{array}$ & $\begin{array}{l}3.17^{* *} \\
(0.05)\end{array}$ & $\begin{array}{l}1.05^{* *} \\
(0.06)\end{array}$ & $\begin{array}{l}-0.31^{* *} \\
(0.07)\end{array}$ & 0.50 \\
\hline \multicolumn{7}{|l|}{ Women } \\
\hline \multicolumn{7}{|l|}{ With children } \\
\hline Elementary & $\begin{array}{l}0.84^{* *} \\
(0.06)\end{array}$ & $\begin{array}{c}-0.66^{* *} \\
(0.12)\end{array}$ & $\begin{array}{c}-2.51^{* *} \\
(0.14)\end{array}$ & $\begin{array}{c}-0.50^{* *} \\
(0.06)\end{array}$ & $\begin{array}{l}1.33^{* *} \\
(0.05)\end{array}$ & 0.47 \\
\hline Secondary & $\begin{array}{l}0.77^{* *} \\
(0.10)\end{array}$ & $\begin{array}{l}0.01^{* *} \\
(0.19)\end{array}$ & $\begin{array}{c}-0.62^{* *} \\
(0.13)\end{array}$ & $\begin{array}{l}1.26^{* *} \\
(0.10)\end{array}$ & $\begin{array}{l}2.12^{* *} \\
(0.10)\end{array}$ & 0.40 \\
\hline Undergraduate & $\begin{array}{l}0.87^{* *} \\
(0.09)\end{array}$ & $\begin{array}{l}0.73^{* *} \\
(0.24)\end{array}$ & $\begin{array}{l}1.51^{* *} \\
(0.15)\end{array}$ & $\begin{array}{l}3.16^{* *} \\
(0.15)\end{array}$ & $\begin{array}{l}2.62^{* *} \\
(0.15)\end{array}$ & 0.37 \\
\hline Graduate & $\begin{array}{l}0.96^{* *} \\
(0.09)\end{array}$ & $\begin{array}{l}1.33^{* *} \\
(0.34)\end{array}$ & $\begin{array}{l}4.12^{* *} \\
(0.25)\end{array}$ & $\begin{array}{l}3.40^{* *} \\
(0.25)\end{array}$ & $\begin{array}{l}1.99^{* *} \\
(0.26)\end{array}$ & 0.42 \\
\hline \multicolumn{7}{|l|}{ Without children } \\
\hline Elementary & $\begin{array}{l}0.85^{* *} \\
(0.05)\end{array}$ & $\begin{array}{l}-0.63^{* *} \\
(0.10)\end{array}$ & $\begin{array}{c}-2.08^{* *} \\
(0.09)\end{array}$ & $\begin{array}{c}-0.40^{* *} \\
(0.05)\end{array}$ & $\begin{array}{l}1.33^{* *} \\
(0.04)\end{array}$ & 0.45 \\
\hline Secondary & $\begin{array}{l}0.73^{* *} \\
(0.07)\end{array}$ & $\begin{array}{c}-0.52^{* *} \\
(0.15)\end{array}$ & $\begin{array}{c}-0.41^{* *} \\
(0.09)\end{array}$ & $\begin{array}{l}1.19^{* *} \\
(0.07)\end{array}$ & $\begin{array}{l}2.11^{* *} \\
(0.07)\end{array}$ & 0.41 \\
\hline Undergraduate & $\begin{array}{l}0.75^{* *} \\
(0.06)\end{array}$ & $\begin{array}{l}0.01^{* *} \\
(0.15)\end{array}$ & $\begin{array}{l}1.17^{* *} \\
(0.09)\end{array}$ & $\begin{array}{l}2.92^{* *} \\
(0.08)\end{array}$ & $\begin{array}{l}2.76^{* *} \\
(0.09)\end{array}$ & 0.37 \\
\hline Graduate & $\begin{array}{l}0.82^{* *} \\
(0.05)\end{array}$ & $\begin{array}{l}0.83^{* *} \\
(0.18)\end{array}$ & $\begin{array}{l}3.67^{* *} \\
(0.12)\end{array}$ & $\begin{array}{l}3.24^{* *} \\
(0.12)\end{array}$ & $\begin{array}{l}2.38^{* *} \\
(0.13)\end{array}$ & 0.34 \\
\hline \multicolumn{7}{|l|}{35 and over } \\
\hline Elementary & $\begin{array}{l}0.74^{* *} \\
(0.05)\end{array}$ & $\begin{array}{c}-0.54^{* *} \\
(0.10)\end{array}$ & $\begin{array}{c}-1.82^{* *} \\
(0.09)\end{array}$ & $\begin{array}{c}-0.37^{* *} \\
(0.05)\end{array}$ & $\begin{array}{l}1.28^{* *} \\
(0.05)\end{array}$ & 0.40 \\
\hline Secondary & $\begin{array}{l}0.78^{* *} \\
(0.08)\end{array}$ & $\begin{array}{l}0.80^{* *} \\
(0.16)\end{array}$ & $\begin{array}{l}0.64^{* *} \\
(0.11)\end{array}$ & $\begin{array}{l}1.90^{* *} \\
(0.10)\end{array}$ & $\begin{array}{l}2.21^{* *} \\
(0.10)\end{array}$ & 0.30 \\
\hline Undergraduate & $\begin{array}{l}1.14^{* *} \\
(0.09)\end{array}$ & $\begin{array}{l}1.67^{* *} \\
(0.20)\end{array}$ & $\begin{array}{l}1.92^{* *} \\
(0.15)\end{array}$ & $\begin{array}{l}3.07^{* *} \\
(0.14)\end{array}$ & $\begin{array}{l}1.83^{* *} \\
(0.15)\end{array}$ & 0.34 \\
\hline Graduate & $\begin{array}{l}0.62^{* *} \\
(0.08)\end{array}$ & $\begin{array}{l}1.66^{* *} \\
(0.25)\end{array}$ & $\begin{array}{l}4.15^{* *} \\
(0.20)\end{array}$ & $\begin{array}{l}3.01^{* *} \\
(0.21)\end{array}$ & $\begin{array}{l}1.64^{* *} \\
(0.22)\end{array}$ & 0.45 \\
\hline \multicolumn{7}{|l|}{ Without children } \\
\hline Elementary & $\begin{array}{l}0.86^{* *} \\
(0.02)\end{array}$ & $\begin{array}{l}0.13^{* *} \\
(0.04)\end{array}$ & $\begin{array}{c}-1.15^{* *} \\
(0.03)\end{array}$ & $\begin{array}{c}-0.12^{* *} \\
(0.02)\end{array}$ & $\begin{array}{l}1.20^{* *} \\
(0.02)\end{array}$ & 0.32 \\
\hline Secondary & $\begin{array}{l}0.82^{* *} \\
(0.04)\end{array}$ & $\begin{array}{l}1.34^{* *} \\
(0.08)\end{array}$ & $\begin{array}{l}1.19^{* *} \\
(0.06)\end{array}$ & $\begin{array}{l}2.21^{* *} \\
(0.06)\end{array}$ & $\begin{array}{l}2.15^{* *} \\
(0.06)\end{array}$ & 0.24 \\
\hline Undergraduate & $\begin{array}{l}0.88^{* *} \\
(0.05)\end{array}$ & $\begin{array}{l}1.60^{* *} \\
(0.12)\end{array}$ & $\begin{array}{l}2.26^{* *} \\
(0.09)\end{array}$ & $\begin{array}{l}3.06^{* *} \\
(0.09)\end{array}$ & $\begin{array}{l}1.88^{* *} \\
(0.10)\end{array}$ & 0.29 \\
\hline Graduate & $\begin{array}{l}0.38^{* *} \\
(0.05)\end{array}$ & $\begin{array}{l}1.62^{* *} \\
(0.14)\end{array}$ & $\begin{array}{l}4.13^{* *} \\
(0.12)\end{array}$ & $\begin{array}{l}2.97^{* *} \\
(0.12)\end{array}$ & $\begin{array}{l}1.91^{* *} \\
(0.13)\end{array}$ & 0.41 \\
\hline
\end{tabular}

$\dagger$ Likelihood ratio index. ${ }^{*}$ Significant at the $5 \%$ level, ${ }^{*}$ significant at the $10 \%$ level. Standard deviations in parentheses. 
Table 4. Choice of workplace location

\begin{tabular}{|c|c|c|c|c|c|}
\hline \multirow[b]{2}{*}{ Groups } & \multicolumn{3}{|c|}{ Explanatory variables } & \multirow[b]{2}{*}{$\mathrm{LRI}^{\dagger}$} & \multirow[b]{2}{*}{$\Delta L R^{\dagger \dagger}$} \\
\hline & Attractiveness & Travel time & $(\text { Travel time })^{2}$ & & \\
\hline \multicolumn{6}{|l|}{ Men } \\
\hline \multicolumn{6}{|l|}{ Under 35} \\
\hline Elementary & $\begin{array}{c}-0.05^{* *} \\
(0.01)\end{array}$ & $\begin{array}{l}1.25^{* *} \\
(0.12)\end{array}$ & $\begin{array}{c}-8.42^{* *} \\
(0.19)\end{array}$ & 0.48 & -7.0 \\
\hline Secondary & $\begin{array}{l}0.06^{* *} \\
(0.01)\end{array}$ & $\begin{array}{l}1.71^{* *} \\
(0.16)\end{array}$ & $\begin{array}{c}-8.37^{* *} \\
(0.24)\end{array}$ & 0.38 & -1.0 \\
\hline Undergraduate & $\begin{array}{l}0.05^{* *} \\
(0.01)\end{array}$ & $\begin{array}{l}1.42^{* *} \\
(0.14)\end{array}$ & $\begin{array}{c}-7.07^{* *} \\
(0.20)\end{array}$ & 0.28 & 6.0 \\
\hline Graduate & $\begin{array}{l}0.13^{* *} \\
(0.01)\end{array}$ & $\begin{array}{l}1.26^{* *} \\
(0.12)\end{array}$ & $\begin{array}{c}-5.89^{* *} \\
(0.17)\end{array}$ & 0.21 & 114.6 \\
\hline \multicolumn{6}{|l|}{35 and over } \\
\hline Elementary & $\begin{array}{l}0.04^{* *} \\
(0.01)\end{array}$ & $\begin{array}{l}1.78^{* *} \\
(0.08)\end{array}$ & $\begin{array}{c}-8.76^{* *} \\
(0.12)\end{array}$ & 0.43 & 1.0 \\
\hline Secondary & $\begin{array}{l}0.21^{* *} \\
(0.01)\end{array}$ & $\begin{array}{l}1.91^{* *} \\
(0.13)\end{array}$ & $\begin{array}{c}-8.39^{* *} \\
(0.19)\end{array}$ & 0.33 & -6.0 \\
\hline Undergraduate & $\begin{array}{l}0.15^{* *} \\
(0.01)\end{array}$ & $\begin{array}{l}1.88^{* *} \\
(0.13)\end{array}$ & $\begin{array}{c}-7.79^{* *} \\
(0.20)\end{array}$ & 0.29 & 25.0 \\
\hline Graduate & $\begin{array}{l}0.29^{* *} \\
(0.01)\end{array}$ & $\begin{array}{l}1.69^{* *} \\
(0.11)\end{array}$ & $\begin{array}{c}-7.11^{* *} \\
(0.15)\end{array}$ & 0.25 & 272.0 \\
\hline \multicolumn{6}{|l|}{ Women } \\
\hline \multicolumn{6}{|l|}{ Under 35} \\
\hline Elementary & $\begin{array}{l}0.04^{*} \\
(0.02)\end{array}$ & $\begin{array}{l}0.54^{* *} \\
(0.24)\end{array}$ & $\begin{array}{c}-7.97^{* *} \\
(0.39)\end{array}$ & 0.53 & -2.0 \\
\hline Secondary & $\begin{array}{l}0.20^{* *} \\
(0.03)\end{array}$ & $\begin{array}{l}-0.22 \\
(0.29)\end{array}$ & $\begin{array}{c}-6.27^{* *} \\
(0.46)\end{array}$ & 0.42 & 0.1 \\
\hline Undergraduate & $\begin{array}{l}0.16^{* *} \\
(0.02)\end{array}$ & $\begin{array}{l}-0.48^{*} \\
(0.28)\end{array}$ & $\begin{array}{c}-5.80^{* *} \\
(0.43)\end{array}$ & 0.39 & 6.8 \\
\hline Graduate & $\begin{array}{l}0.11^{* *} \\
(0.02)\end{array}$ & $\begin{array}{l}-0.35 \\
(0.30)\end{array}$ & $\begin{array}{c}-4.91^{* *} \\
(0.44)\end{array}$ & 0.30 & 13.9 \\
\hline \multicolumn{6}{|l|}{ Without children } \\
\hline Elementary & $\begin{array}{l}0.06^{* *} \\
(0.02)\end{array}$ & $\begin{array}{l}0.51^{* *} \\
(0.20)\end{array}$ & $\begin{array}{c}-7.84^{* *} \\
(0.30)\end{array}$ & 0.51 & -4.0 \\
\hline Secondary & $\begin{array}{l}0.23^{* *} \\
(0.02)\end{array}$ & $\begin{array}{c}0.21 \\
(0.21)\end{array}$ & $\begin{array}{c}-6.80^{* *} \\
(0.32)\end{array}$ & 0.42 & -1.0 \\
\hline Undergraduate & $\begin{array}{l}0.24^{* *} \\
(0.01)\end{array}$ & $\begin{array}{l}0.34^{* *} \\
(0.15)\end{array}$ & $\begin{array}{c}-6.02^{* *} \\
(0.22)\end{array}$ & 0.32 & 25.0 \\
\hline Graduate & $\begin{array}{l}0.11^{* *} \\
(0.01)\end{array}$ & $\begin{array}{l}0.50^{* *} \\
(0.15)\end{array}$ & $\begin{array}{c}-5.34^{* *} \\
(0.21)\end{array}$ & 0.25 & 45.1 \\
\hline \multicolumn{6}{|l|}{35 and over } \\
\hline Elementary & $\begin{array}{l}0.17^{* *} \\
(0.02)\end{array}$ & $\begin{array}{l}0.58^{* *} \\
(0.22)\end{array}$ & $\begin{array}{c}-8.14^{* *} \\
(0.36)\end{array}$ & 0.54 & -7.0 \\
\hline Secondary & $\begin{array}{l}0.30^{* *} \\
(0.03)\end{array}$ & $\begin{array}{l}-0.07 \\
(0.29)\end{array}$ & $\begin{array}{c}-6.97^{* *} \\
(0.45)\end{array}$ & 0.46 & 2.5 \\
\hline Undergraduate & $\begin{array}{l}0.19^{* *} \\
(0.02)\end{array}$ & $\begin{array}{c}0.21 \\
(0.28)\end{array}$ & $\begin{array}{c}-6.92^{* *} \\
(0.42)\end{array}$ & 0.42 & 13.3 \\
\hline Graduate & $\begin{array}{l}0.20^{* *} \\
(0.03)\end{array}$ & $\begin{array}{l}-0.42 \\
(0.28)\end{array}$ & $\begin{array}{c}-5.37^{* *} \\
(0.40)\end{array}$ & 0.35 & 20.2 \\
\hline \multicolumn{6}{|l|}{ Without children } \\
\hline Elementary & $\begin{array}{l}0.15^{* *} \\
(0.01)\end{array}$ & $\begin{array}{l}0.69^{* *} \\
(0.11)\end{array}$ & $\begin{array}{c}-8.27^{* *} \\
(0.17)\end{array}$ & 0.55 & -28.0 \\
\hline Secondary & $\begin{array}{l}0.30^{* *} \\
(0.01)\end{array}$ & $\begin{array}{l}0.35^{* *} \\
(0.16)\end{array}$ & $\begin{array}{c}-7.30^{* *} \\
(0.24)\end{array}$ & 0.45 & 23.0 \\
\hline Undergraduate & $\begin{array}{l}0.16^{* *} \\
(0.01)\end{array}$ & $\begin{array}{l}0.60^{* *} \\
(0.17)\end{array}$ & $\begin{array}{c}-7.15^{* *} \\
(0.26)\end{array}$ & 0.41 & 20.0 \\
\hline Graduate & $\begin{array}{l}0.17^{* *} \\
(0.03)\end{array}$ & $\begin{array}{l}0.68^{* *} \\
(0.17)\end{array}$ & $\begin{array}{c}-6.66^{* *} \\
(0.24)\end{array}$ & 0.36 & 22.0 \\
\hline
\end{tabular}

${ }^{\dagger}$ Likelihood ratio index. ${ }^{\dagger} \Delta L R$ is the difference between the likelihood ratio (LR) of the model of workplace location estimated with the attractiveness measure and the LR of the model estimated with the size measure (total number of jobs). ${ }^{* *}$ Significant at the $5 \%$ level, ${ }^{*}$ significant at the $10 \%$ level. Standard deviations in parentheses. 
Table 5. Sample size by tenure and dwelling type

\begin{tabular}{lccc}
\hline & \multicolumn{2}{c}{ Dwelling type $^{1}$} & \\
\cline { 2 - 3 } Tenure & Apartment & Single dwelling & Total \\
\hline Owner & 17,047 & 16,121 & 33,168 \\
& & & $(37.96 \%)$ \\
Tenant & 51,104 & 3,095 & 54,199 \\
& & & $(62.04 \%)$ \\
\hline Total & 68,151 & 19,216 & 87,367 \\
& $(78.01 \%)$ & $(21.99 \%)$ & $(100 \%)$ \\
\hline
\end{tabular}

${ }^{1}$ All the detached-single unit and semi-detached dwellings are defined as "houses," otherwise the dwellings are defined as "flats".

Sample size of 87,367 one-worker households living and working in Île-de-France.

Source: general population census for Île-de-France. Insee, 1999. 
Table 6. Choice of residential location (I)

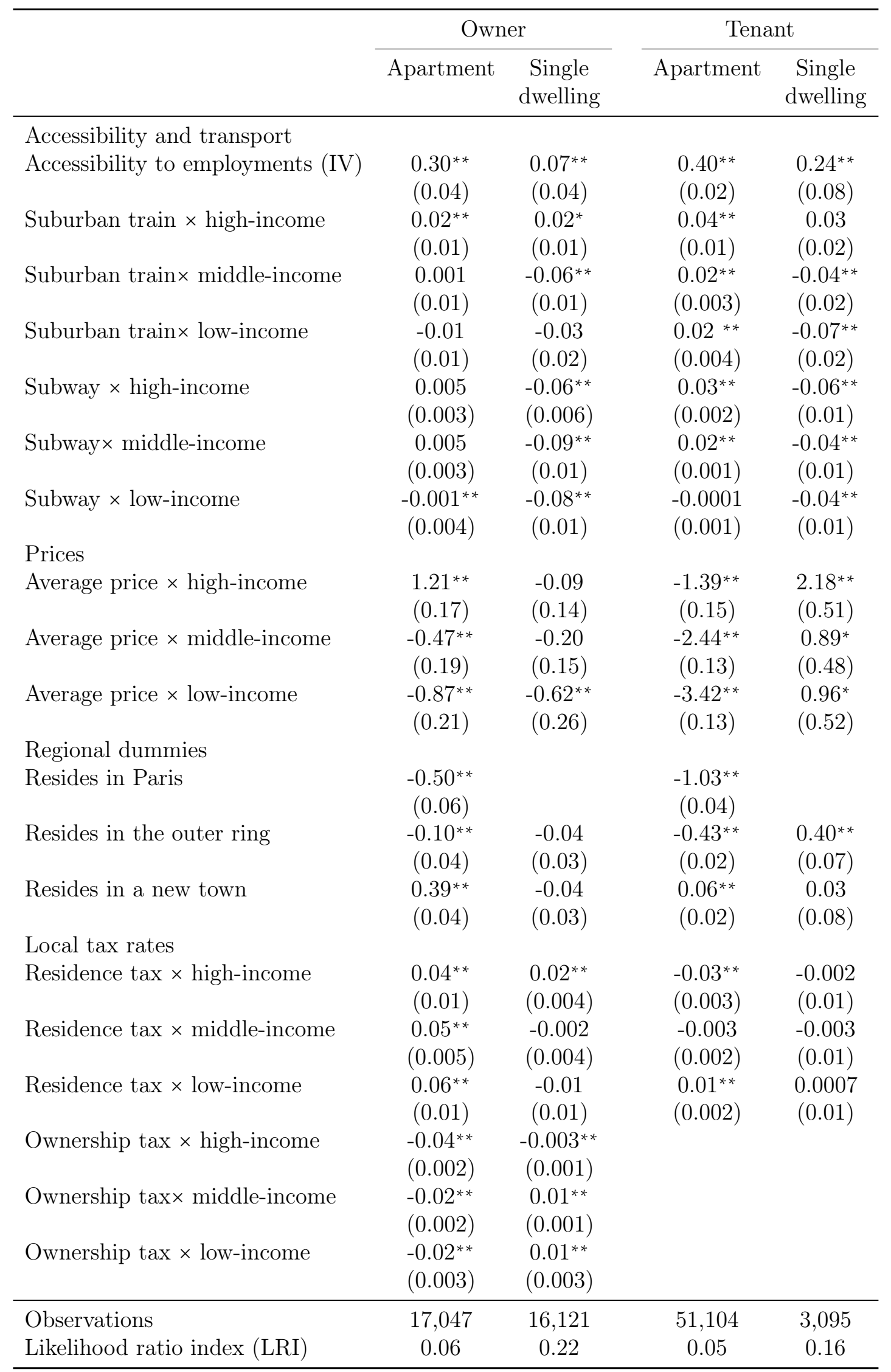

** Significant at the $5 \%$ level, * significant at the $10 \%$ level. Standard deviations in parentheses. 
Table 7. Choice of residential location (II)

\begin{tabular}{|c|c|c|c|c|}
\hline & \multicolumn{2}{|c|}{ Owner } & \multicolumn{2}{|c|}{ Tenant } \\
\hline & Apartment & $\begin{array}{c}\text { Single } \\
\text { dwelling }\end{array}$ & Apartment & $\begin{array}{c}\text { Single } \\
\text { dwelling }\end{array}$ \\
\hline \multicolumn{5}{|l|}{ Land use and local amenities } \\
\hline Density & $\begin{array}{l}0.01^{* *} \\
(0.01)\end{array}$ & $\begin{array}{c}-0.07^{* *} \\
(0.01)\end{array}$ & $\begin{array}{l}0.02^{* *} \\
(0.01)\end{array}$ & $\begin{array}{c}-0.07^{* *} \\
(0.01)\end{array}$ \\
\hline$\%$ noise (surface) & $\begin{array}{c}0.19 \\
(0.13)\end{array}$ & $\begin{array}{c}-0.34^{* *} \\
(0.11)\end{array}$ & $\begin{array}{c}-0.07^{* *} \\
(0.07)\end{array}$ & $\begin{array}{c}-0.57^{* *} \\
(0.26)\end{array}$ \\
\hline$\%$ water (surface under) & $\begin{array}{c}0.10 \\
(0.30)\end{array}$ & $\begin{array}{c}-2.44^{* *} \\
(0.35)\end{array}$ & $\begin{array}{l}0.99^{* *} \\
(0.17)\end{array}$ & $\begin{array}{l}-0.61 \\
(0.77)\end{array}$ \\
\hline$\%$ water $\times$ children dummy & $\begin{array}{c}0.38 \\
(0.80)\end{array}$ & $\begin{array}{c}1.11 \\
(0.72)\end{array}$ & $\begin{array}{c}0.08 \\
(0.37)\end{array}$ & $\begin{array}{l}2.54^{* *} \\
(1.30)\end{array}$ \\
\hline$\%$ priority schools (surface) & $\begin{array}{l}-0.06 \\
(0.04)\end{array}$ & $\begin{array}{c}-0.12^{* *} \\
(0.04)\end{array}$ & $\begin{array}{c}-0.08^{* *} \\
(0.02)\end{array}$ & $\begin{array}{c}0.15 \\
(0.10)\end{array}$ \\
\hline$\%$ priority schools $\times$ children dummy & $\begin{array}{l}0.25^{* *} \\
(0.08)\end{array}$ & $\begin{array}{l}-0.13^{*} \\
(0.08)\end{array}$ & $\begin{array}{l}0.45^{* *} \\
(0.04)\end{array}$ & $\begin{array}{l}-0.03 \\
(0.15)\end{array}$ \\
\hline$\%$ educational buildings (surface) & $\begin{array}{c}0.52 \\
(0.51)\end{array}$ & $\begin{array}{c}-11.14^{* *} \\
(1.16)\end{array}$ & $\begin{array}{l}0.62^{* *} \\
(0.31)\end{array}$ & $\begin{array}{r}-5.97^{* *} \\
(2.14)\end{array}$ \\
\hline$\%$ education $\times$ children dummy & $\begin{array}{l}-0.07 \\
(1.51)\end{array}$ & $\begin{array}{l}-0.30 \\
(1.69)\end{array}$ & $\begin{array}{l}3.40^{* *} \\
(0.63)\end{array}$ & $\begin{array}{c}-8.03^{* *} \\
(3.21)\end{array}$ \\
\hline Neighborhood composition & & & & \\
\hline$\%$ foreign $\mathrm{HHs}$ & $\begin{array}{l}8.30^{* *} \\
(0.58)\end{array}$ & $\begin{array}{l}8.52^{* *} \\
(0.54)\end{array}$ & $\begin{array}{l}5.23^{* *} \\
(0.23)\end{array}$ & $\begin{array}{l}6.59^{* *} \\
(0.97)\end{array}$ \\
\hline$\%$ foreign $\mathrm{HHs} \times$ below secondary & $\begin{array}{l}3.88^{* *} \\
(0.60)\end{array}$ & $\begin{array}{c}0.60 \\
(0.50)\end{array}$ & $\begin{array}{l}3.00^{* *} \\
(0.28)\end{array}$ & $\begin{array}{c}1.74 \\
(1.13)\end{array}$ \\
\hline$\%$ foreign $\mathrm{HHs} \times$ undergraduate & $\begin{array}{c}0.22 \\
(0.42)\end{array}$ & $\begin{array}{l}-0.40 \\
(0.42)\end{array}$ & $\begin{array}{c}0.19 \\
(0.22)\end{array}$ & $\begin{array}{l}-1.44 \\
(0.93)\end{array}$ \\
\hline$\%$ foreign $\mathrm{HHs} \times$ graduate & $\begin{array}{c}-1.21^{* *} \\
(0.42)\end{array}$ & $\begin{array}{c}-1.39^{* *} \\
(0.47)\end{array}$ & $\begin{array}{c}-1.73^{* *} \\
(0.24)\end{array}$ & $\begin{array}{l}-2.1^{* *} \\
(1.06)\end{array}$ \\
\hline$\%$ high-income HHs $\times$ high-income & $\begin{array}{l}1.31^{* *} \\
(0.25)\end{array}$ & $\begin{array}{l}2.68^{* *} \\
(0.19)\end{array}$ & $\begin{array}{l}-0.07 \\
(0.17)\end{array}$ & $\begin{array}{l}1.39^{* *} \\
(0.47)\end{array}$ \\
\hline$\%$ low-income HHs $\times$ low-income & $\begin{array}{c}-0.90^{* *} \\
(0.43)\end{array}$ & $\begin{array}{l}-0.60 \\
(0.55)\end{array}$ & $\begin{array}{l}0.38^{* *} \\
(0.19)\end{array}$ & $\begin{array}{c}0.81 \\
(0.83)\end{array}$ \\
\hline$\%$ middle-income HHs $\times$ middle-income & $\begin{array}{c}-1.53^{* *} \\
(0.63)\end{array}$ & $\begin{array}{l}2.89^{* *} \\
(0.41)\end{array}$ & $\begin{array}{l}1.60^{* *} \\
(0.30)\end{array}$ & $\begin{array}{c}0.73 \\
(0.81)\end{array}$ \\
\hline$\%$ of 1 person $\mathrm{HHs} \times 1$ person $\mathrm{HH}$ & $\begin{array}{l}4.20^{* *} \\
(0.18)\end{array}$ & $\begin{array}{c}-1.17^{* *} \\
(0.39)\end{array}$ & $\begin{array}{l}4.27^{* *} \\
(0.10)\end{array}$ & $\begin{array}{c}0.92 \\
(0.57)\end{array}$ \\
\hline$\%$ of 2 persons $\mathrm{HHs} \times 2$ people $\mathrm{HH}$ & $\begin{array}{l}-1.31 \\
(0.83)\end{array}$ & $\begin{array}{l}2.12^{* *} \\
(0.68)\end{array}$ & $\begin{array}{l}-0.17 \\
(0.47)\end{array}$ & $\begin{array}{l}-1.29 \\
(1.52)\end{array}$ \\
\hline$\%$ of $3+$ persons $\mathrm{HHs} \times 3+$ people $\mathrm{HH}$ & $\begin{array}{c}0.19 \\
(0.20)\end{array}$ & $\begin{array}{l}3.39^{* *} \\
(0.21)\end{array}$ & $\begin{array}{l}1.23^{* *} \\
(0.11)\end{array}$ & $\begin{array}{l}2.91^{* *} \\
(0.43)\end{array}$ \\
\hline$\%$ young $\mathrm{HHs} \times$ young $\mathrm{HH}$ & $\begin{array}{l}2.41^{* *} \\
(0.51)\end{array}$ & $\begin{array}{c}-3.76^{* *} \\
(0.84)\end{array}$ & $\begin{array}{l}4.25^{* *} \\
(0.23)\end{array}$ & $\begin{array}{l}-1.09 \\
(0.96)\end{array}$ \\
\hline$\%$ middle-age $\mathrm{HHs} \times$ middle-age $\mathrm{HH}$ & $\begin{array}{c}-0.62^{* *} \\
(0.24)\end{array}$ & $\begin{array}{l}1.75^{* *} \\
(0.24)\end{array}$ & $\begin{array}{l}-0.28^{*} \\
(0.15)\end{array}$ & $\begin{array}{l}-0.29 \\
(0.49)\end{array}$ \\
\hline$\%$ old HHs $\times$ old HH & $\begin{array}{l}3.65^{* *} \\
(0.37)\end{array}$ & $\begin{array}{l}2.30^{* *} \\
(0.31)\end{array}$ & $\begin{array}{l}1.55^{* *} \\
(0.29)\end{array}$ & $\begin{array}{l}1.54^{*} \\
(0.91)\end{array}$ \\
\hline Observations & 17,047 & 16,121 & 51,104 & 3,095 \\
\hline Likelihood ratio index (LRI) & 0.0598 & 0.2166 & 0.0553 & 0.1639 \\
\hline
\end{tabular}

Note: $\mathrm{HH}=$ Household Head. ${ }^{* *}$ Significant at the $5 \%$ level, ${ }^{*}$ significant at the $10 \%$ level. Standard deviations in parentheses. 
Figure 1. Three-level nested structure of the choice of residential location, workplace, and type of employment

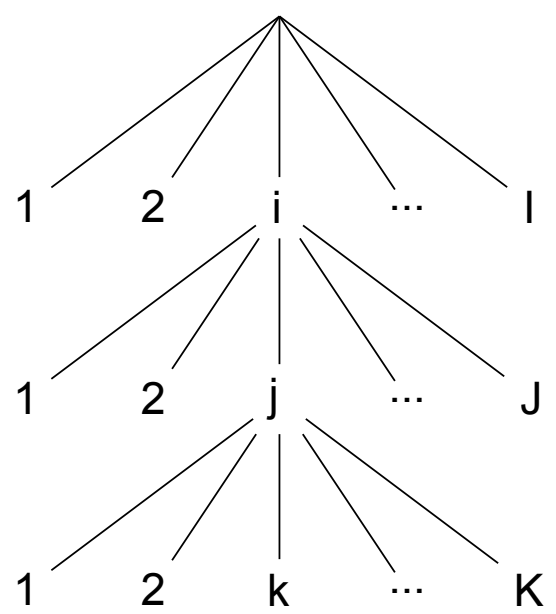

3. Highest level:

residential location

2. Intermediate level:

workplace

1. Lowest level: type of employment 

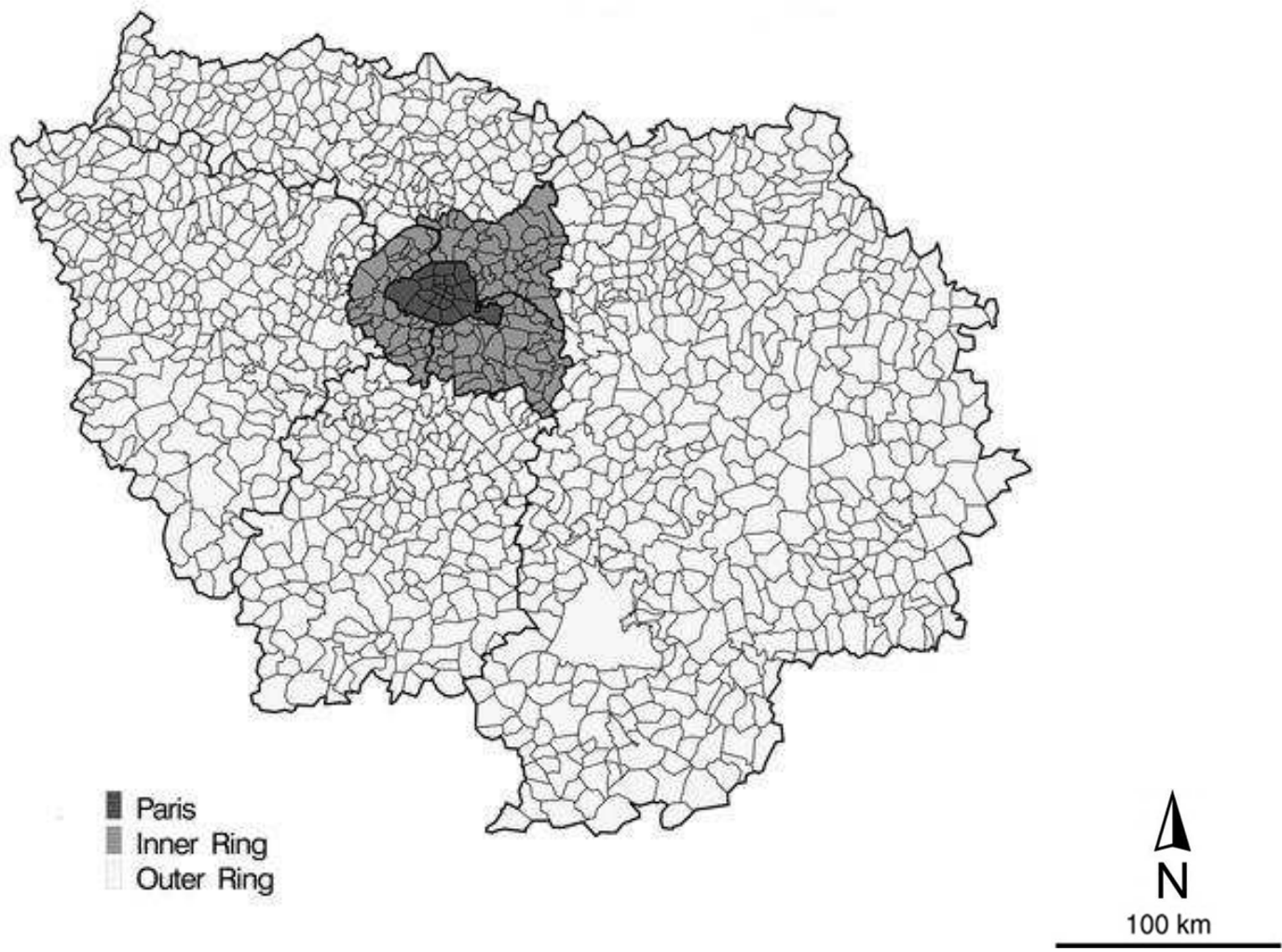

Figure 2. Île-de-France (1,300 communes) 

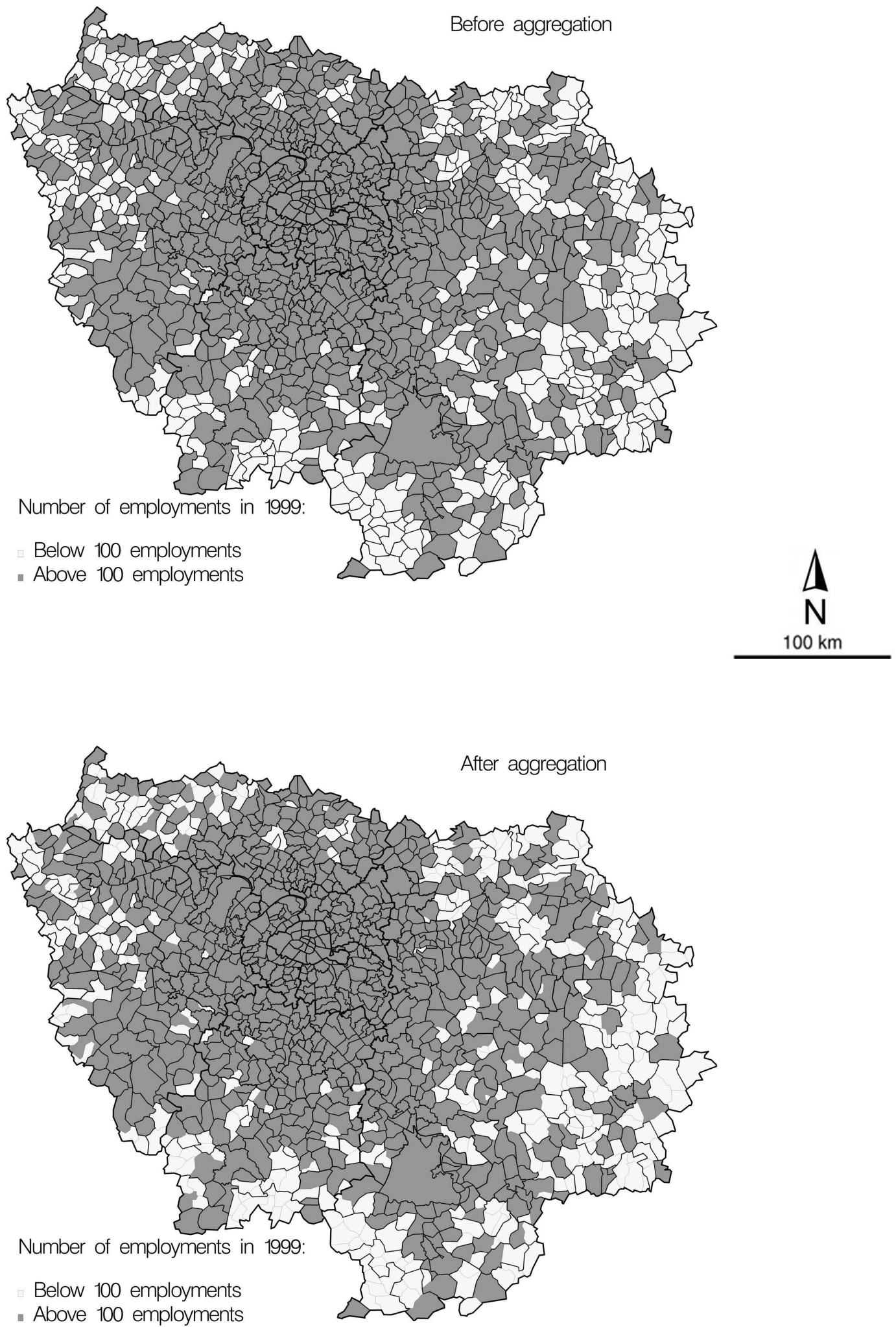

Figure 3. Communes by total number of employments (950 grouped communes with more than 100 employments) 
Figure 4. Three-level nested structure of the choice of residential location, workplace, and type of employment; segmentation by tenure and dwelling type
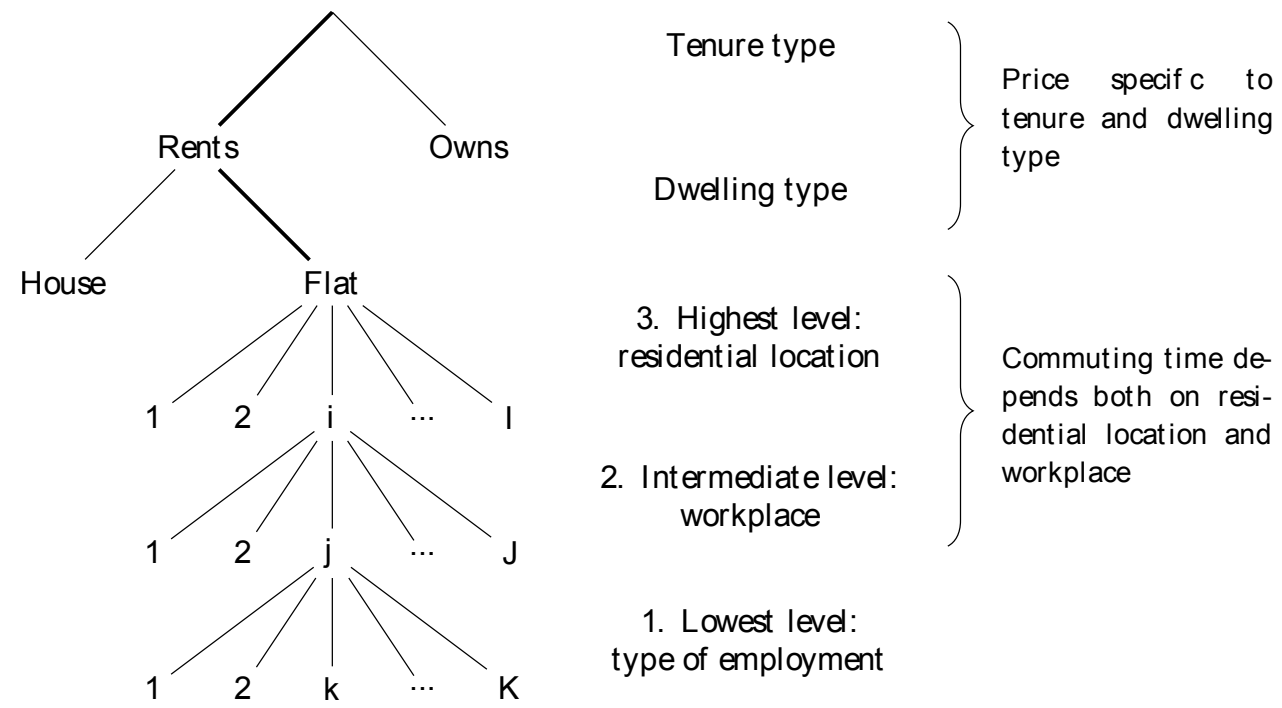

3. Highest level: residential location

2. Intermediate level: pends both on residential location and workplace workplace

1. Lowest level: type of employment 
Women
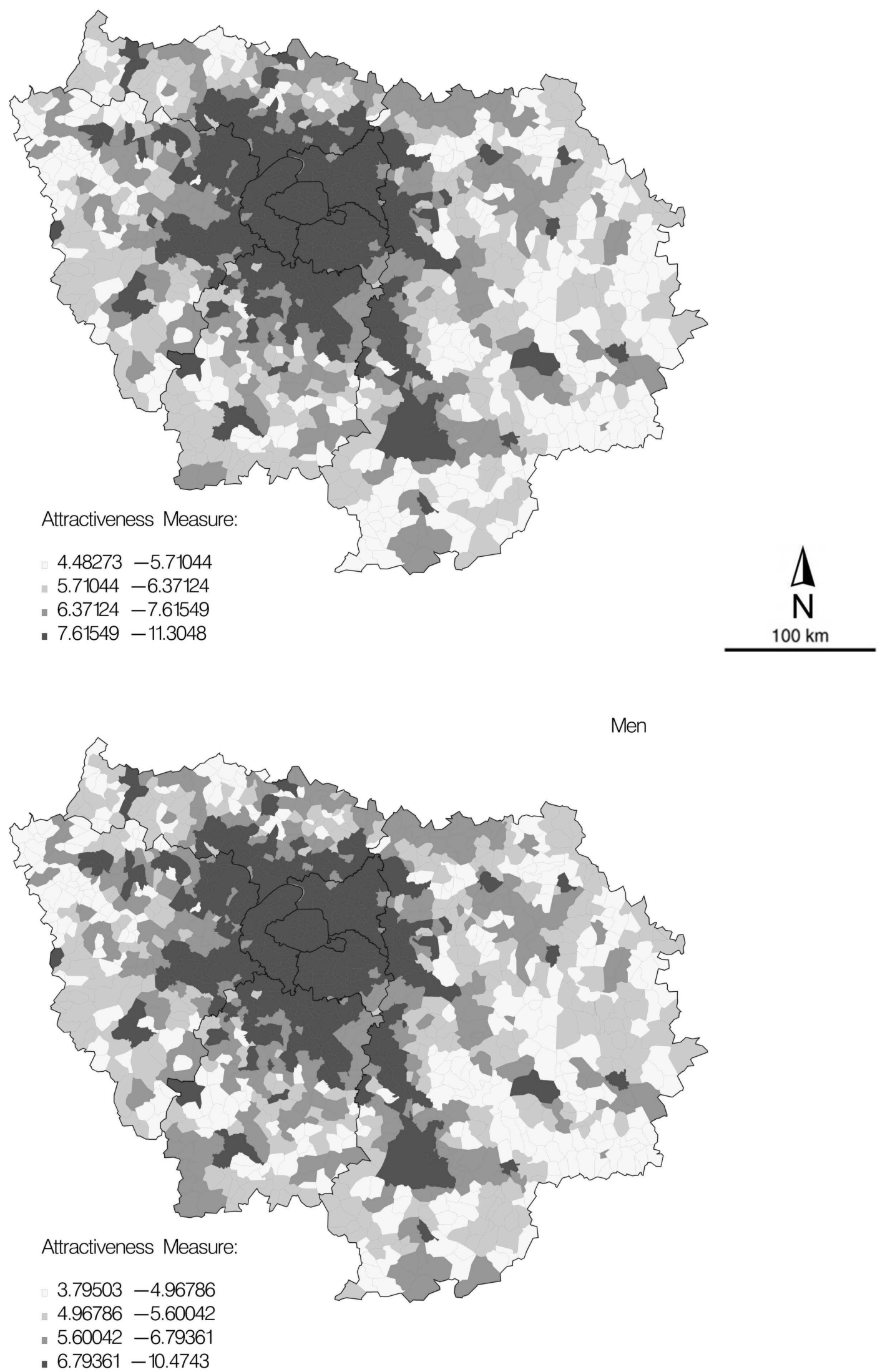

Figure 5. Attractiveness of communes for workers by sex 
Elementary \& Middle School
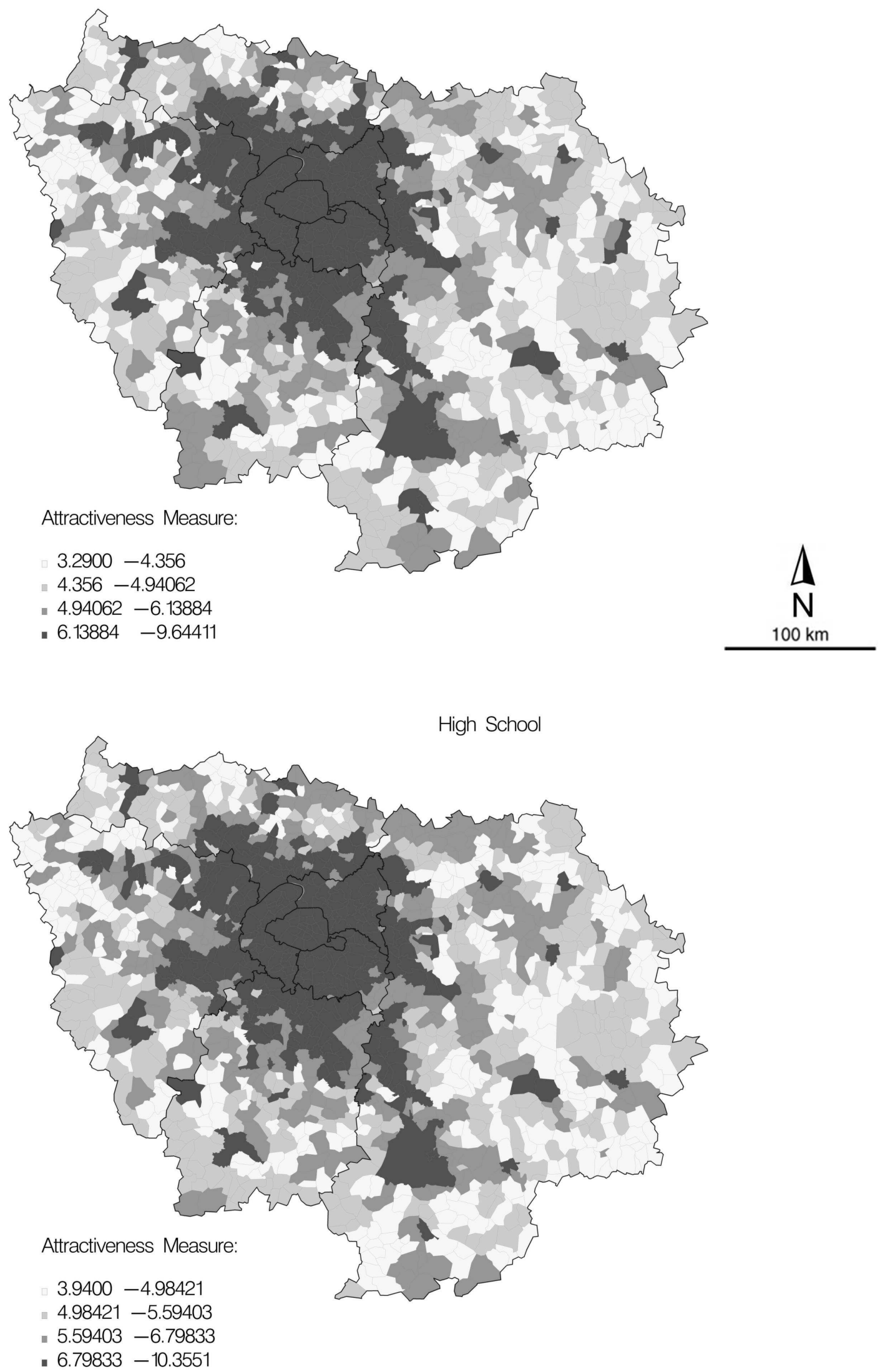

Figure 6. Attractiveness of communes for workers by level of education (I) 
Undergraduate
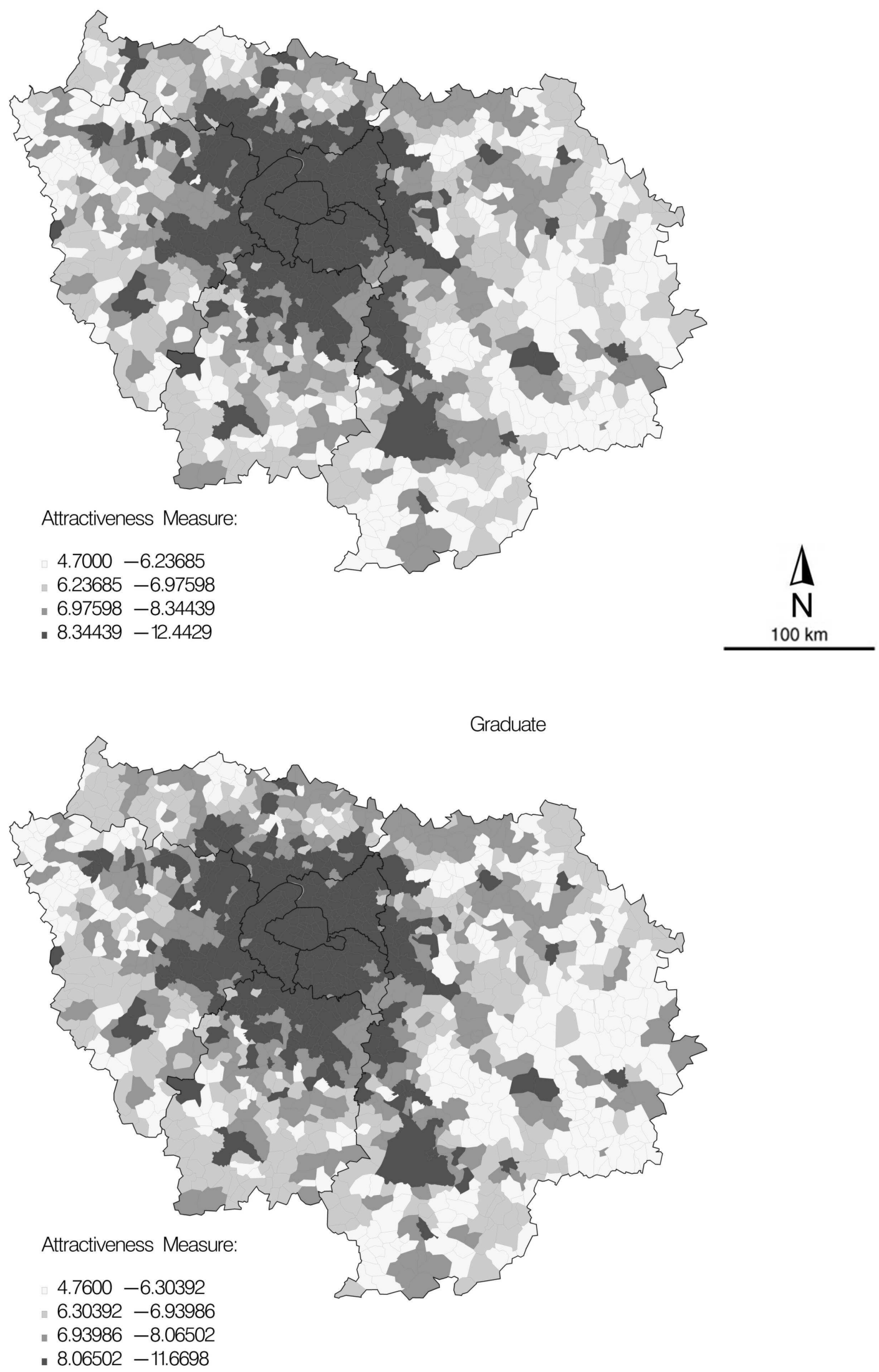

Figure 7. Attractiveness of communes for workers by level of education (II) 
Women
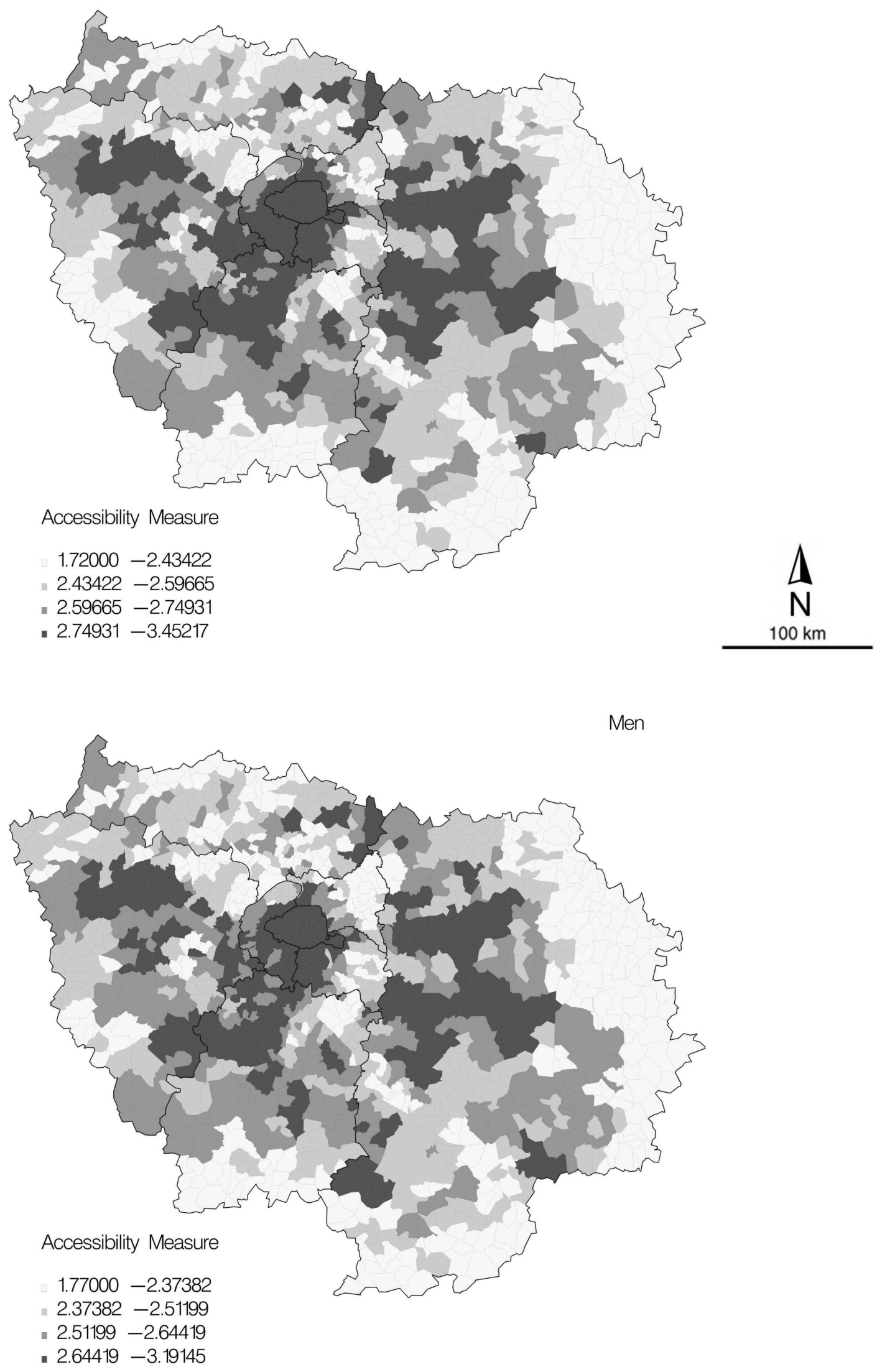

Figure 8. Accessibility to employments by sex 
Elementary \& Middle School

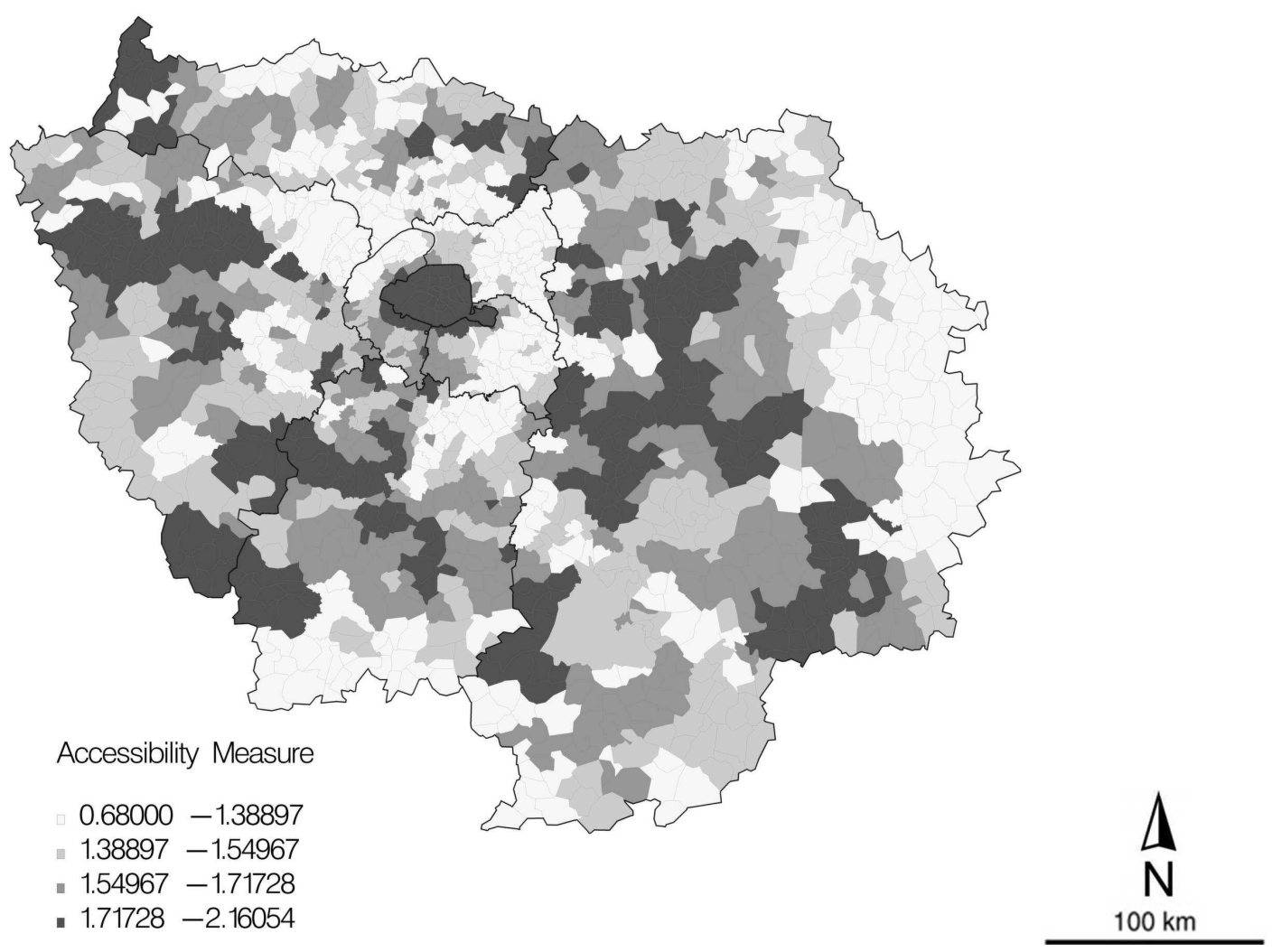

High School

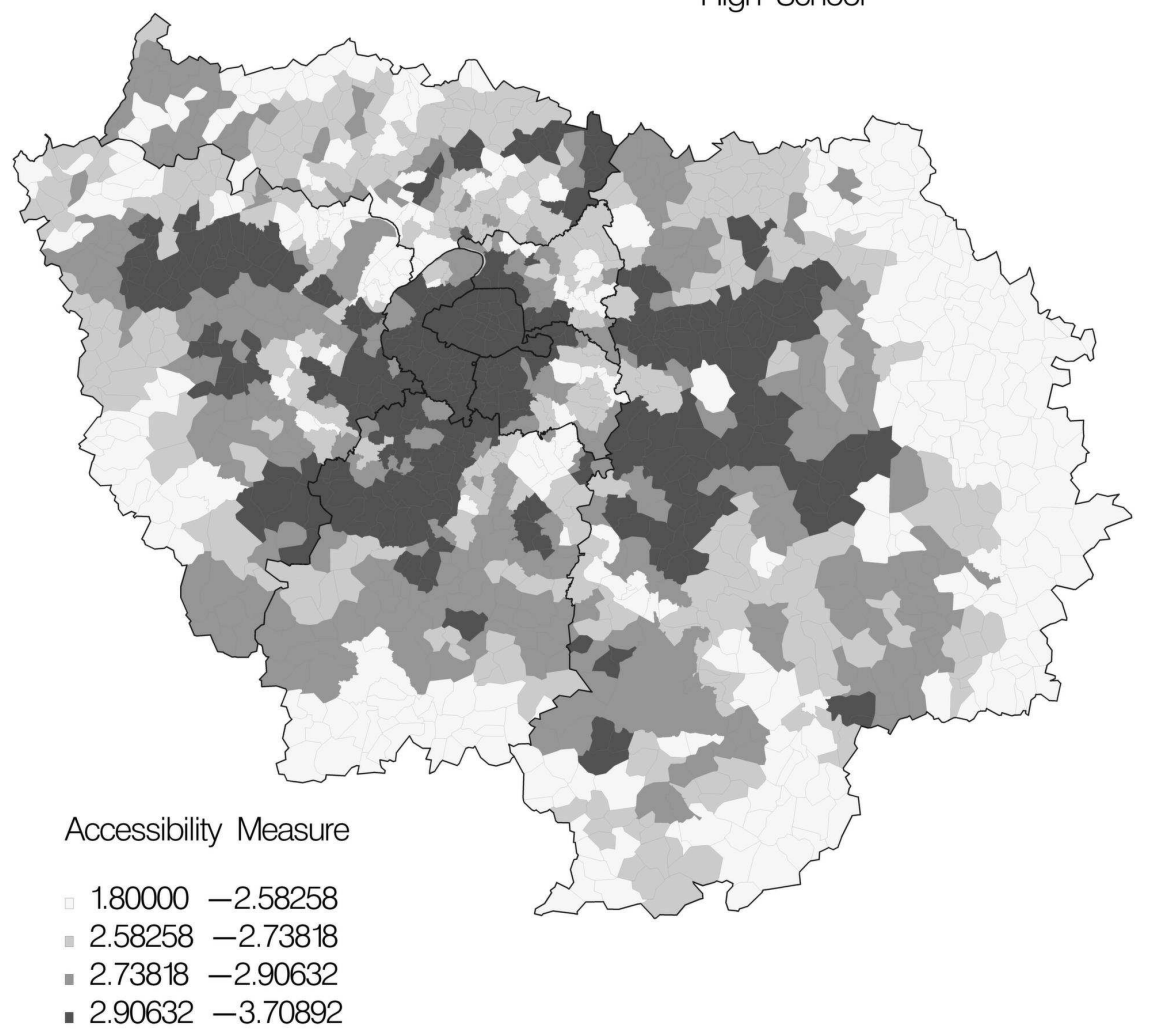

Figure 9. Accessibility to employments by level of education (I) 
Undergraduate
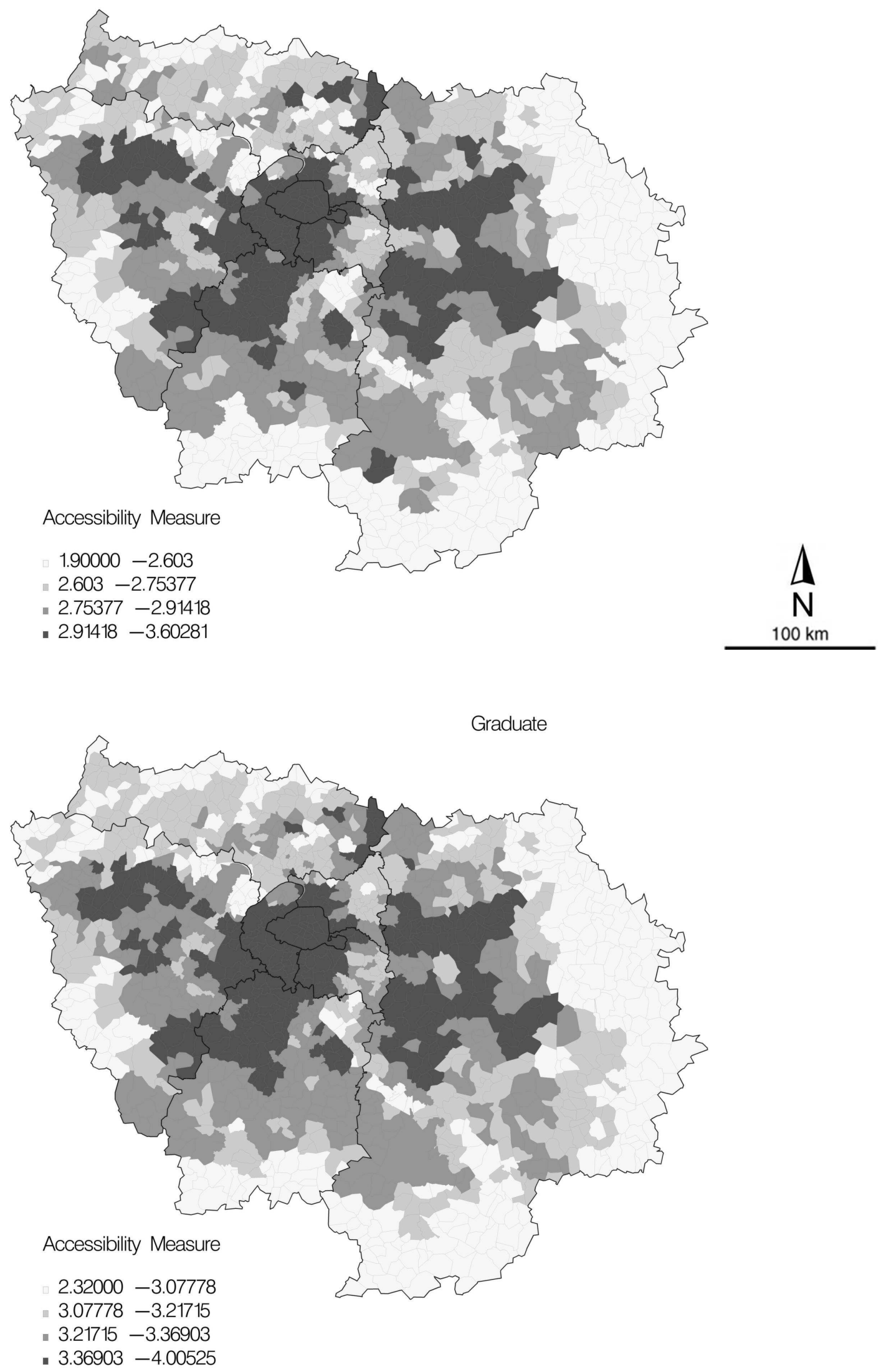

Figure 10. Accessibility to employments by level of education (II) 